Working Paper/Document de travail 2014-41

\title{
Improving Public Equity Markets? \\ No Pain, No Gain
}

by Katya Kartashova 
Bank of Canada Working Paper 2014-41

September 2014

\title{
Improving Public Equity Markets? No Pain, No Gain
}

\author{
by \\ Katya Kartashova \\ Canadian Economic Analysis Department \\ Bank of Canada \\ Ottawa, Ontario, Canada K1A OG9 \\ kkartashova@bankofcanada.ca
}

Bank of Canada working papers are theoretical or empirical works-in-progress on subjects in economics and finance. The views expressed in this paper are those of the author.

No responsibility for them should be attributed to the Bank of Canada. 


\section{Acknowledgements}

I thank Cristina Arellano, Frederico Belo, David Lagakos, Ellen McGrattan, Narayana Kocherlakota, Fabrizio Perri, Amil Petrin, Chris Phelan, Facundo Piguillem, Yuichiro Waki, Mike Waugh and Hakki Yazici for their comments. All remaining errors are mine alone. 


\begin{abstract}
This paper quantifies the effects of improving public equity markets on macroeconomic aggregates and welfare. I use an open-economy extension of Angeletos (2007), where entrepreneurs face idiosyncratic productivity risk in privately held firms. They can diversify by investing in publicly traded firms, but their operation is costly. These costs can vary across different economies. To quantify the effect of the differences and impose discipline, I parameterize the model using Ecuadorian and Chilean firm-level and aggregate data. Lower equity costs result in improvement of economic aggregates, but have differential welfare effects. Entrepreneurs suffer a loss, while workers gain.
\end{abstract}

JEL classification: E44, G11, O11, O16

Bank classification: Financial institutions; Financial markets; Development economics

\title{
Résumé
}

Dans cette étude, l'auteure quantifie l'incidence d'une amélioration des marchés boursiers sur les agrégats macroéconomiques et le bien-être. Elle a recours à un modèle d'économie ouverte, qui développe le modèle d'Angeletos (2007): ainsi, dans les sociétés fermées, les entrepreneurs sont confrontés à un risque idiosyncrasique en matière de productivité. Ils peuvent réduire ce risque par la diversification en investissant dans des sociétés ouvertes, dont l'exploitation est toutefois plus coûteuse à divers degrés selon les économies. Pour mesurer l'effet des écarts et imposer une discipline, l'auteure paramètre le modèle au moyen de données sur les entreprises et de données agrégées provenant de l'Équateur et du Chili. Une baisse des coûts des capitaux propres entraîne une amélioration des agrégats, mais exerce un effet différencié sur le bien-être : elle se traduit par une perte pour les entrepreneurs et un gain pour les travailleurs.

Classification JEL : E44, G11, O11, O16

Classification de la Banque : Institutions financières; Marchés financiers; Économie du développement 


\section{Introduction}

The relationship between financial and economic development has been commonly studied in cross-country regressions. These regressions have found a positive association between different measures of financial development and macroeconomic outcomes $\square^{1}$ However, it is difficult to establish the direction or magnitude of any causal link between the two using regression analysis alone. Public equity represents one form of financial development. It provides the benefit of better sharing of production risks in the economy. At the same time, operating publicly traded firms involves costs. Arguably, these operations are more costly in less financially developed countries, with the costs reflecting an exogenous component of financial development. In this paper, I address the following question: "What are the quantitative aggregate and distributional effects of reducing the costs of operating a publicly traded firm?"

To study the effects of lowering public equity costs, I use an open-economy version of Angeletos (2007). The economy is populated with workers and entrepreneurs. This division allows for differential welfare effects for the owners of capital and labor production factors. Entrepreneurs face idiosyncratic productivity risk in privately held firms. They can diversify away from this risk by investing in a portfolio of public equity. Publicly traded firms operate the same production technology as privately held firms, but have to incur a cost of operating in the publicly traded sector. These costs are broadly defined to include transaction, information and enforcement costs. Thus, in their investments, entrepreneurs trade off the risk associated with privately held firms versus the cost of diversification in publicly traded firms. With these elements, the processes for the productivity shock of entrepreneurs and public equity costs are key to the parameterization of the model $]^{2}$

\footnotetext{
${ }^{1}$ See Demirguç-Kunt and Levine $(2008)$ for an excellent summary of past and more recent findings in the empirical literature.

${ }^{2}$ Given the set-up using Angeletos (2007), the return differential associated with the risk of investing in privately held companies is fixed and exogenous. Other set-ups could be used to endogenize the extent of risk sharing and the risk borne by entrepreneurs, for example, in a contracting framework with effort/monitoring. These modelling choices are rather different, with the current choice undoubtedly quite simple, but complemented well by the analysis in the quantitative part, as discussed next.
} 
The focus of the quantitative study is on Ecuador and Chile. One reason for this is the availability of data for determining the key parameters in the model. In particular, the production data for privately held firms needed to estimate the productivity process of entrepreneurs are not widely available; Ecuador and Chile represent an exception in this case $3^{3}$ Equally important for the purpose of this paper is the difference between the two countries in terms of their economic and financial development. The Chilean public equity market is more developed in terms of such measures as stock market capitalization, turnover and total value traded; it also outperforms the public equity market in Ecuador in terms of regulatory and institutional indicators ${ }^{1}$ Chile's per capita income is substantially higher, measuring as much as four times the level in Ecuador. One can exploit these differences and assess the quantitative importance of the gap in financial development by considering a model-based experiment of exogenous reduction in Ecuador's public equity costs to their Chilean level. More generally, however, the findings in this paper can be interpreted by viewing Ecuador and Chile as representative of the developing economies with different levels of financial development.

To conduct the counterfactual experiment, the model is first calibrated to Chile and then

\footnotetext{
${ }^{3}$ In line with the model set-up, the results of production function regressions using these data are used to calibrate the degree of idiosyncratic uncertainty faced by entrepreneurs. A different project using joint production and balance-sheet data on privately held and publicly traded companies could have involved identifying the extent to which lack of access to external financial markets (associated with private-public status) might directly influence firm-level decisions. These, in turn, could have been used to inform the model. For example, in line with this thinking, Asker, Farre-Mensa, and Ljungqvist (2014) empirically show that in the United States investment sensitivity of privately held companies exceeds that of publicly traded companies. Using additional tests to discriminate among a number of different theories, they conclude that the difference in investment sensitivities could be attributed to a higher propensity of publicly traded companies to suffer agency costs. Arellano, Bai, and Zhang (2012) - discussed in more detail in the literature review - take this idea to the cross-country comparison and study the effect of variation in countries' financial market development on firms' financing choices and growth using comprehensive firm-level data for a crosssection of European countries with different levels of financial development. Their paper does not directly focus on the differences between privately held and publicly traded companies in these countries or across countries.

${ }^{4}$ In particular, between 1995 and 2006, the stock market capitalization to GDP in Chile on average was about $84 \%$ of GDP and in Ecuador it was $7.8 \%$. The value of stocks traded as a percentage of GDP over the same period was on average about $8.4 \%$ in Chile and $0.4 \%$ in Ecuador. And lastly, the turnover ratio, which is the value of stocks traded as a percentage of value of stocks outstanding, was $12 \%$ in Chile versus $6.8 \%$ in Ecuador. In terms of regulatory and institutional infrastructure, Chile has long had the highest indicators in the region.
} 
recalibrated for some parameter values to Ecuador. Given the structure of the entrepreneur's problem, I cannot use simple ordinary least squares (OLS) to estimate the productivity process. Its realization in each period fully translates into the entrepreneur's choice of labor input given capital installed. To address the issue of endogeneity, I use the proxy variable approach suggested by Olley and Pakes (1996) and Levinsohn and Petrin (2003). I then take the estimated sample variance of the predicted residuals as the measure of the productivity risk in entrepreneurial firms. I use the model to infer the costs of operating a publicly traded firm from the relative size of the publicly traded and entrepreneurial sectors in the data. With data from two countries, I impose discipline on the exogenous reduction in public equity costs in the experiment.

Qualitatively, I find a positive effect of lower public equity costs on macroeconomic aggregates, and a differential effect on the welfare of workers and entrepreneurs. The aggregate and distributional effects are tightly linked. The intuition for both is best illustrated in the simple benchmark case of a small open economy: a reduction in public equity costs raises demand for capital and labor in the economy. With a fixed labor supply and an elastic supply of capital at the world interest rate, the capital-labor ratio and wages of the workers increase. Workers consume their current labor income and can only benefit from the wage increase. Entrepreneurs face two returns: a return on investment in their own firms and a return on their public equity investment. With higher wages, the cost of labor hired by entrepreneurs in their own firms increases, while returns fall. At the same time, public equity returns do not change, since these are pinned down by the world interest rate. Thus, with lower returns in their own firms, entrepreneurs face worse investment opportunities and cannot be better off. Note that society as a whole benefits from lower public equity costs with more investment in the publicly traded equity. None of this gain, however, accrues to entrepreneurs. The scarce labor factor gets all of the benefits.

Quantitatively, lower public equity costs have a small impact on macroeconomic aggregates, but the distributional effects appear to be quite large. The $15 \%$ reduction in public 
equity costs in Ecuador to their Chilean level is associated with an increase in the aggregate capital stock by $5.4 \%$. At the same time, aggregate wages and output increase by $1.9 \%$. This is the same magnitude as the increase in the aggregate consumption of workers. The welfare gain of workers from the reduction in public equity costs is equal to $3.2 \%$ in lifetime consumption equivalents. The welfare loss of entrepreneurs assuming the same initial wealth level is about $9.9 \%$. The sign of the welfare effects for entrepreneurs is independent of their position in the initial distribution, which only determines the size of the effect. Using an empirical distribution of wealth from the data, I obtain a more accurate assessment of the size of welfare outcomes of entrepreneurs.

The paper is organized as follows. Section 2 provides a context for the paper in the existing literature. Section 3 introduces the model. Section 4 characterizes the main features of equilibrium. Section 5 describes the set-up for the experiment and discusses the

qualitative effects on macroeconomic aggregates and welfare in a benchmark case. Section 6 introduces firm-level data and the procedure for estimation of the firm productivity process. Section 7 summarizes the choice of functional forms and parameters of the model. Section 8 summarizes the quantitative effects on the aggregates and individual welfare. Section 9 concludes.

\section{Related Literature}

This paper is most closely related to the literature that studies the effects of better risk diversification associated with financial development on economic development, including but not limited to papers by Greenwood and Jovanovic (1990), Obstfeld (1994), and Devereux and Smith (1994). In particular, Greenwood and Jovanovic (1990) consider an AK model of endogenous growth with risky individual production technology and costly financial intermediation. As in this paper, the agents in the economy face a trade-off between risk and the cost of diversification. Since the focus in the model is on endogenous growth and 
intermediation, the framework does not allow its straightforward application in quantitative analysis:5 In terms of welfare implications, the equilibrium in Greenwood and Jovanovic (1990) is efficient, and conducting the experiment of lowering intermediation costs similar to this paper would probably have trivial welfare outcomes. For these reasons, the framework used in this paper might be better suited for quantitative evaluation, but at the expense of endogenous financial intermediation. Unlike Greenwood and Jovanovic (1990), Obstfeld (1994) and Devereux and Smith (1994) consider representative agent economies where the only source of investment uncertainty is at the aggregate level.

In the model of this paper, markets are incomplete with respect to idiosyncratic investment risk. Covas (2006) and Meh and Quadrini (2006) consider similar environments but ask different questions. In particular, in Meh and Quadrini (2006), markets are endogenously incomplete due to private information about the realization of the shocks. In the presence of these informational asymmetries, they focus on the macroeconomic and welfare implications of different risk-sharing arrangements. Covas (2006) does not address the source of market incompleteness, but rather focuses on its effects on capital accumulation with borrowing constraints and persistent investment shocks. He also considers a version of the model with a corporate (traded) sector. This sector is introduced to quantify more accurately the effect of risk on capital accumulation. In the model, the two sectors differ technologically, with the corporate sector employing both capital and labor of the workers. Since the entrepreneurial sector uses only capital, unlike in this paper, the returns of entrepreneurs will be unaffected by any changes in economy-wide wages. The entrepreneurial technology also exhibits decreasing returns to scale. With the scarce entrepreneurial factor in the experiment of lowering public equity costs considered here, entrepreneurs would be able to claim part of the benefits accruing to the workers ${ }^{6}$

\footnotetext{
${ }^{5}$ In particular, in an AK permanent growth environment, the non-intermediated sector would be predicted to become extinct over a sufficiently long time period as the relative cost of intermediation falls. For quantitative aggregate evaluation, one would at least need to modify its production structure, possibly in line with Atje and Jovanovic (1993), who provide its empirical test. With aggregate uncertainty and idiosyncratic shocks, however, this would make the framework analytically intractable.

6 This paper also bears a relationship to the literature on differential taxation of corporate and non-
} 
In its focus on exogenous changes to the model environment, this paper is closely related to, e.g., Antunes, Cavalcanti, and Villamil (2008). In a model of occupational choice, its authors investigate the effects of exogenous differences in intermediation costs and contract enforcement in credit markets on output per capita, total credit and income inequality. Their analysis focuses on the cross-section of developed and developing economies. The benchmark model is calibrated to the United States, and the only difference between countries under consideration is in terms of the size of their intermediation costs and degree of contract enforcement. These differences are then mapped into the long-run measures of economic development. The occupational choice approach is also used by Giné and Townsend (2003). Similar to this paper, the authors perform their quantitative analysis for Thailand - a country of interest for which extensive micro and macro data are available - and assess the aggregate and distributional consequences associated with the process of financial liberalization. An alternative growth accounting approach is pursued in Jeong and Townsend (2007). The focus of these papers, however, is on the extensive margin of participation in the financial sector. Financial liberalization relaxes regulatory and other legal requirements and allows access to the financial system for a segment of the population that would have otherwise been excluded.7

While the focus of this paper is on the aggregate and distributional effects on welfare, a closely related paper that studies the impact of cross-country variation in financial market development on firms' financing choices and growth is Arellano, Bai, and Zhang (2012). Using comprehensive firm-level data sets for a number of countries, they show that in less financially developed economies, small firms grow faster and have lower leverage than large firms.

corporate sectors going back to Harberger $(1962)$. Entrepreneurial risk and liquidity constraints have been added to the literature by Meh (2008). In the occupational choice framework, he focuses on the trade-off between variability of income in the entrepreneurial sector and double taxation of income in the corporate sector. The two papers, however, are very different in the treatment of entrepreneurial risk and in the resulting trade-off studied.

${ }^{7}$ More specifically, they focus on reforms that lead to less-restricted licensing requirements for financial institutions (both foreign and domestic), the reduction of excess capitalization requirements, and enhanced ability to open new branches, which are modelled as resulting in greater access to deposits and credit for the population. 
As financial development improves, the gap in growth rates of small and large firms closes, but the difference in leverage rises. They use a quantitative model with financial frictions and a risk of default to explain the observed cross-country variations in firm size, leverage and growth associated with differences in the level of financial development. Their focus on joint cross-sectional financing and growth patterns explains the difference in modelling approaches, with the Arellano, Bai, and Zhang (2012) model incorporating such important features as default.

\section{Model Description}

The model is an open-economy extension of Angeletos (2007). Time is discrete and infinite, $t \in\{0,1, \ldots\}$. There are two types of agents in the economy: a measure $\chi$ of entrepreneurs, and a measure $1-\chi$ of workers. There is no occupational choice decision, and the division into workers and entrepreneurs is exogenous.

\subsection{The Entrepreneur's Problem}

Entrepreneurs' preferences are given by

$$
E_{0} \sum_{t=0}^{\infty} \beta^{t} \frac{c_{t}^{i^{1-\gamma}}}{1-\gamma}
$$

where $\beta$ is the discount factor and $E_{0}$ is the expectation as of date 0 with respect to the uncertainty facing entrepreneurs. At each date $t$, entrepreneur $i$ chooses consumption, $c_{t}^{i}$, capital investment, $k_{t+1}^{i}$, investment in public equity shares, $x_{t+1}^{i}$, and one-period foreign asset holdings, $b_{t+1}^{i} .^{8}$ Entrepreneurs employ current-period capital $k_{t}^{i}$ and labor $n_{t}^{i}$ in their

\footnotetext{
${ }^{8}$ Here, $b_{t+1}^{i}<0$ refers to a loan from a foreign bank or financial institution. Alternatively, it could be interpreted as the issuance of fixed-income claims in foreign bond markets. The former interpretation would be preferred, however, given that private borrowers are disproportionately important to the market in international bank loans, while sovereigns and other government borrowers primarily rely on the bond market (see Eichengreen and Mody (1999)). In the case of private borrowers, this is particularly true for the manufacturing sector, to which the model will be parameterized later. This relationship with foreign
} 
privately held firms with production technology given by

$$
F\left(k_{t}^{i}, n_{t}^{i}, \eta_{t}^{i}\right)=\eta_{t}^{i}\left(k_{t}^{i}\right)^{\alpha}\left(n_{t}^{i}\right)^{1-\alpha}
$$

where $\eta_{t}^{i}$ is the idiosyncratic productivity shock. The shocks are assumed to be i.i.d. over time and over agents, with a continuous probability density function $h: R_{+} \rightarrow R_{+} \cdot 9$ At any date $t$, capital $k_{t}^{i}$ is a fixed input in the production technology, and $n_{t}^{i}$ is a variable input optimally chosen at the beginning of the period in response to the realization of shock $\eta_{t}^{i}$ given $k_{t}^{i}$. Due to the timing, investment in $k_{t}^{i}$ is risky, and in the absence of markets for equity claims in privately held firms, entrepreneurs bear the investment risk in full. They can diversify away from their firms by investing in public equity capital, $x_{t+1}^{i}$, and foreign assets, $b_{t+1}^{i}$, both of which are assumed to be riskless. ${ }^{10}$

The budget set of an entrepreneur is given by

$$
\begin{gathered}
c_{t}^{i}+k_{t+1}^{i}+b_{t+1}^{i}+x_{t+1}^{i} \leq \pi_{t}^{i}+R_{t} b_{t}^{i}+R_{x t} x_{t}^{i} \\
\pi_{t}^{i}=\eta_{t}^{i}\left(k_{t}^{i}\right)^{\alpha}\left(n_{t}^{i}\right)^{1-\alpha}-w_{t} n_{t}^{i}+(1-\delta) k_{t}^{i} ; c_{t}^{i}, k_{t+1}^{i} \geq 0 \\
\bar{b}_{t+1}^{i} \equiv b_{t+1}^{i}+x_{t+1}^{i} \geq-k_{t+1}^{i},
\end{gathered}
$$

where $R_{t}$ is the interest rate associated with foreign asset holdings and $R_{x t}$ is the return to public equity. Entrepreneurs receive residual income in their privately held firms, $\pi_{t}^{i}$, defined below, and investment income from their net safe-asset holdings. In this section, the time endowment of entrepreneurs is set to 0, so they do not earn any labor income either in their own firms or in the publicly traded sector 11 With returns on safe assets equalized in financial intermediaries is described in greater detail in Section 3.5

${ }^{9}$ In the quantitative part, the shocks will be assumed to be $\ln \eta_{t}^{i} \sim N\left(0, \sigma_{\eta}^{2}\right)$.

${ }^{10}$ In the real world, investments in public equity are rarely thought of as riskless, given the fluctuations in the returns to the aggregate public equity indices. However, only public equity allows the idiosyncratic risks to be diversified through trade, while both public and private equities are subject to aggregate risks. The focus of this paper is on the insurance of idiosyncratic risks through public equity investments.

${ }^{11}$ Section 7 considers a more general set-up with the time endowment $\nu \in[0,1]$ of an entrepreneur. 
the absence of arbitrage opportunities, in equilibrium safe investments can only be pinned down in the aggregate, and not at the individual level of the entrepreneur. The borrowing constraint of entrepreneurs in $(4)$ is never binding in equilibrium $\sqrt{12}$

\subsection{The Worker's Problem}

The preferences of worker $i, w$ are given by

$$
\sum_{t=0}^{\infty} \beta^{t} \frac{c_{t}^{i, w^{1-\gamma}}}{1-\gamma}
$$

There is no expectation as in (1), since the workers in the model do not face any uncertainty. Unlike entrepreneurs, workers do not have access to production technology in privately held firms. They can hold positive amounts of assets abroad and invest in public equity. Workers receive labor income from selling one unit of time endowment in the competitive labor market, and investment income from asset holdings. They choose how much to consume/save, and their asset portfolio subject to budget feasibility:

$$
c_{t}^{i, w}+x_{t+1}^{i, w}+b_{t+1}^{i, w} \leq R_{x t} x_{t}^{i, w}+R_{t} b_{t}^{i, w}+w_{t} \text { and } c_{t}^{i, w}, b_{t+1}^{i, w}, x_{t+1}^{i, w} \geq 0 .
$$

As above, the portfolio of safe assets of each worker would be indeterminate, with $\bar{b}_{t+1}^{i, w} \equiv$ $b_{t+1}^{i, w}+x_{t+1}^{i, w}$. However, faced with no uncertainty, workers choose to consume all of their income and do not save/invest in the steady-state equilibrium of this incomplete markets economy with $\beta R<1$.

\footnotetext{
${ }^{12}$ In particular, this eliminates any consideration of default in the model, with defaultable debt potentially quantitatively important as a source of external finance in countries with limited access to equity market financing. Defaultable debt in this case provides the owners with a discretion similar to that available through a dividend policy of publicly traded companies, i.e. of insuring negative realizations of the shocks by nonrepayment and non-servicing of the debt outstanding. Thus, depending on the costs, the ability to default could lower the benefits to entrepreneurs associated with access to external equity financing. Arellano, Bai, and Zhang (2012) develop a model with financing frictions and default that focuses on the implications of differences in financial development on firm growth and financing.
} 


\subsection{Returns to Public Equity Investments}

While entrepreneurs are able to diversify away productivity risk by investing in publicly traded firms, these investments have effectively lower average productivity compared to private equity investments. The difference in productivities is meant to capture the many costs associated with operating a publicly traded firm, which include but are not limited to costs of communication with investors; accounting, auditing and financial reporting costs; and costs of legal services. These costs may vary across countries as a result of different policies, and are thought to decrease in the process of development 13

Formally, the relationship between average productivities of investments in private and public equity is given by

$$
R_{x t}=\frac{F_{K t}+1-\delta}{1+\tau}
$$

where $F_{K t}$ is the average productivity of the private equity investment, and $\tau$ embodies the cost associated with public equity investment. Higher $\tau$ results in lower average productivity and lower returns to public equity. Firms in the publicly traded sector employ the aggregates of $X_{t}$ in capital and $L_{t}$ in labor inputs.

\subsection{The Entrepreneur's Trade-off}

Equity investments of entrepreneurs are determined as part of a portfolio decision problem. Private equity has a higher average return and is risky (with $\sigma_{\eta}^{2}>0$ ), while public equity has a lower average return (with $\tau>0$ ) and is risk-free. Thus, the shares of these investments in an entrepreneur's asset portfolio would depend on the relationship between $\sigma_{\eta}^{2}$ and equity cost $\tau$.

\footnotetext{
${ }^{13}$ Although the costs of operating publicly traded firms may fluctuate over time in developed countries with periods of increases, they would still be expected to remain below those in the developing countries.
} 


\subsection{Foreign Sector}

There is a continuum of foreign agents, who supply resources according to the following schedule:14

$$
R= \begin{cases}\left.g\left(\left|\frac{B}{Y}\right|\right\}\right) & \text { if } B<0 \\ R_{w} & \text { if } B \geq 0\end{cases}
$$

where $\mathrm{B}=\int_{i \in[0,1]} b^{i} d i$ denotes the economy's net foreign asset position, $\frac{B}{Y}$ is the net foreign asset-to-income ratio, $g(\cdot)$ is increasing in $\frac{B}{Y}<0$, and $R_{w}$ is a base interest rate 15 In this specification, $R$ is external to the individual decisions of the agents. When the economy is a net creditor, i.e., $B>0$, it faces a constant base rate $R_{w}$. When the economy is a net debtor, i.e., $B<0$, its borrowing rate is increasing in the amount of total debt normalized by income ${ }^{16}$

\section{Equilibrium Characterization}

\subsection{Equilibrium Definition}

Definition 1 Given initial asset holdings of workers and entrepreneurs, the equilibrium of the economy is defined as deterministic sequences of wages $\left\{w_{t}\right\}_{t=0}^{\infty}$, interest rates $\left\{R_{t}\right\}_{t=0}^{\infty}$, aggregate quantities $\left\{C_{t}, C_{t}^{w}, K_{t+1}, X_{t+1}, Y_{t}, B_{t+1}, N_{t}, L_{t}\right\}_{t=0}^{\infty}$, deterministic plans $\left\{c_{t}^{i, w}, \bar{b}_{t+1}^{i, w}\right\}_{t=0}^{\infty}$ for workers $i \in(\chi, 1]$, and collections of contingent plans $\left\{c_{t}^{i}, \bar{b}_{t+1}^{i}, n_{t}^{i}, k_{t+1}^{i}\right\}_{t=0}^{\infty}$ for entrepreneurs $i \in[0, \chi]$, such that the following conditions are satisfied:

\footnotetext{
${ }^{14}$ Foreign agents are banks, or financial institutions more generally.

${ }^{15} R_{w}$ does not have to be constant and can vary with changes in credit market conditions, e.g., many international loans are priced off LIBOR, which fluctuates over time. $R_{w}$ can be interpreted as the world interest rate as well.

${ }^{16}$ The functional relationship between the debt-to-income ratio $\frac{B}{Y}<0$ and the interest rate will be specified in Section 7. In particular, it captures the debt-elastic external interest rate in the small open-economy literature.
} 
(i) Given sequences of wages $\left\{w_{t}\right\}_{t=0}^{\infty}$ and interest rates $\left\{R_{t}\right\}_{t=0}^{\infty}$, and initial endowment $b_{0}^{i}+x_{0}^{i}$ and $k_{0}^{i},\left\{c_{t}^{i}, n_{t}^{i}, \bar{b}_{t+1}^{i}, k_{t+1}^{i}\right\}_{t=0}^{\infty}$ solves entrepreneur $i$ 's problem for $\forall i \in[0, \chi]$;

(ii) Given sequences of wages $\left\{w_{t}\right\}_{t=0}^{\infty}$ and interest rates $\left\{R_{t}\right\}_{t=0}^{\infty}$, and initial endowment $b_{0}^{i, w}+x_{0}^{i, w}$, deterministic plans $\left\{c_{t}^{i, w}, \bar{b}_{t+1}^{i, w}\right\}_{t=0}^{\infty}$ solve worker $i$ 's problem for $\forall i \in(\chi, 1]$;

(iii) Aggregate accounting identities hold.

(iv) Labor market clears, $\forall t \geq 0: \quad N_{t}+L_{t}=1-\chi$

(v) Pairs $\left\{R_{t}, \frac{B_{t}}{Y_{t}}\right\}_{t=0}^{\infty}$ satisfy the foreign interest rate schedule;

(vi) Resource constraint holds, $\forall t \geq 0$ :

$C_{t}+C_{t}^{w}+K_{t+1}+(1+\tau) X_{t+1}+B_{t+1}=F\left(K_{t}, N_{t}, \bar{\eta}\right)+F\left(X_{t}, L_{t}, \bar{\eta}\right)+(1-\delta)\left(K_{t}+X_{t}\right)+R_{t} B_{t}$.

In this definition, $F\left(K_{t}, N_{t}, \bar{\eta}\right)$ is the output produced in the entrepreneurial sector, and $F\left(X_{t}, L_{t}, \bar{\eta}\right)$ is the output in the publicly traded sector ${ }^{17}$

\subsection{Individual Behavior}

Due to timing, the profit-maximization problem of an entrepreneur in a privately held firm is static. Given prices, as shown in Lemma 1, Appendix A, the profit-maximizing choice of labor, $n_{t}^{i}$, and resulting profits, $\pi_{t}^{i}$, are linear in capital $k_{t}^{i}$. Abstracting from $i$ subscripts,

$$
n_{t}=n\left(\eta_{t}, w_{t}\right) k_{t} \text { and } \pi_{t}=\left(R_{k}\left(\eta_{t}, w_{t}\right)+1-\delta\right) k_{t}
$$

where $n(\eta, w)=\arg \max _{l}[F(\eta, 1, l)-w l]$ and $R_{k}(\eta, w)=\max _{l}[F(\eta, 1, l)-w l]$ are labor input and profit per unit of capital, respectively.

With $\omega_{t} \equiv R_{k t} k_{t}+R_{t} b_{t}+R_{x t} x_{t}$ denoting entrepreneurial wealth at date $t$, as shown in Lemma 2, Appendix A, optimal consumption, investment in risky private equity, $k_{t+1}$, and safe public equity and foreign asset holdings, $\bar{b}_{t+1}$, are linear in wealth:

$$
c_{t}=\left(1-\varsigma_{t}\right) \omega_{t}, k_{t+1}=\varsigma_{t} \phi_{t} \omega_{t}, \bar{b}_{t+1}=\varsigma_{t}\left(1-\phi_{t}\right) \omega_{t},
$$

\footnotetext{
${ }^{17}$ The total output of the economy in equilibrium is $Y=F\left(X_{t}, L_{t}, \bar{\eta}\right)+F\left(K_{t}, N_{t}, \bar{\eta}\right)=\bar{\eta}\left(K_{t}+X_{t}\right)^{\alpha}(1-$ $\chi)^{1-\alpha}$.
} 
where $\varsigma_{t}$ is the savings rate, and $\phi_{t}$ and $1-\phi_{t}$ are portfolio shares of risky and risk-free assets. All agents choose the same fraction of wealth for consumption, $1-\varsigma$, and the same portfolio allocation, $\phi$.

The optimal decision rules in (7) help highlight the difference between the incomplete markets model of this paper and the class of Aiyagari/Bewley models. In Aiyagari/Bewley models, shocks to labor income enter additively, similar to endowment shocks. With standard constant relative risk aversion (CRRA) preferences, in particular, agents' marginal propensity to consume declines with the level of wealth, and the optimal consumption function is concave. This reflects strictly positive precautionary demand for savings due to uncertainty associated with future labor income. Concavity implies that the aggregate dynamics depend on the whole wealth distribution in the economy preventing the use of closed-form solutions.

In the model of this paper, as in the original model of Angeletos (2007), uncertainty is associated with the rate of return on investment (no labor-income risk). With the same standard CRRA preferences, the consumption function is linear in wealth. The two wellknown cases when the marginal propensity to consume out of wealth is independent of wealth are: (i) the CARA utility if all of the risk is to labor income (no rate-of-return risk), and (ii) CRRA utility if all of the risk is rate-of-return risk (no labor-income risk). This model is an example of $(i i)$. All entrepreneurs choose to save the same fraction of their wealth and allocate the same fraction of the portfolio to risky assets. With linearity in the optimal decision rules, all of the aggregates in the economy are independent of the distributions. With exact aggregation results, the model is highly analytically tractable, unlike the class of Aiyagari/Bewley models.

\subsection{Aggregate Steady State}

The aggregate steady-state quantities and prices in the open economy facing the foreign lending schedule in (5) are uniquely determined for a given vector $\left\{\alpha, \sigma_{\eta}^{2}, \delta, \beta, \gamma, \chi\right\}$ of parameters of technology, preferences and population structure, as a function of the proportional public 
equity cost $\tau$ (see Lemma 3, Appendix A).

While the steady state is well defined in terms of the aggregates, there is no stationary distribution for the cross-section. At steady-state prices, the log of wealth of the agents follows a random walk. To get around the problem of non-stationarity, one can introduce a positive probability of death of entrepreneurs. In each period, entrepreneurs who die are replaced with an equal mass of new agents, with their assets distributed uniformly among the newly born. Since the qualitative findings in this paper would not be affected by this modification, it will not be pursued here.

\section{$5 \quad$ Qualitative Results}

In this section, I explore the comparative statics with respect to the proportional public equity $\operatorname{cost} \tau$.

\subsection{Aggregate Implications and Welfare Effects}

Benchmark case. One can use the case of a small open economy $\left.\left(g\left(\left|\frac{B}{Y}\right|\right\}\right)=c>1, \forall \frac{B}{Y}\right)$ to determine the sign of the differential welfare effects associated with lower public equity costs for workers and entrepreneurs, and derive responses of the aggregates in closed form.

Aggregate implications. Consider a change in $\tau=\bar{\tau}$ by $1+\epsilon, \epsilon$ small, in the economy facing a constant world interest rate. In equilibrium, returns on safe assets are equalized:

$$
R_{w}=\frac{F_{K}+(1-\delta)}{1+\bar{\tau}(1+\epsilon)}
$$

where $F_{K}$ is the average product of aggregate capital in privately held firms 18

With $\mathrm{d} \epsilon<0$, the percentage decrease in the marginal product of capital and the aggregate

\footnotetext{
${ }^{18}$ Note that, in equilibrium, aggregate capital-labor ratios in publicly traded and entrepreneurial sectors would be the same and would also be equal to the aggregate capital-labor ratio in the economy.
} 
return in the entrepreneurial sector are given by

$$
\operatorname{dlog} \mathrm{F}_{\mathrm{K}}=\frac{R_{w} \bar{\tau}}{R_{w}(1+\bar{\tau}(1+\epsilon))+\delta-1} \mathrm{~d} \epsilon,
$$

where $R_{w}(1+\bar{\tau}(1+\epsilon))+\delta-1>0$.

At the same time, with $\alpha<1$ and $\mathrm{d} \epsilon<0$, the aggregate capital stock increases by

$$
\mathrm{d} \log (\mathrm{K}+\mathrm{X})=\frac{\mathrm{d} \log \mathrm{F}_{\mathrm{K}}}{\alpha-1} \mathrm{~d} \epsilon
$$

Then, with a fixed labor supply, the aggregate output increases by fraction $\alpha$ of the increase in the aggregate capital, and so do the wages of the workers, which they consume in equilibrium.

Welfare effects. The welfare effects of lower public equity costs are tightly linked to the aggregate effects discussed above. Theorem 1 shows that the sign of the effects is different for workers and entrepreneurs. Its proof is included in Appendix A; only the intuition is provided in this section.

Theorem 1 Consider two economies with the same vector of parameter values of technology $\{\alpha, \delta\}$ facing the world interest rate. Let the initial distribution of wealth of entrepreneurs $\left\{k_{0}^{i}, \bar{b}_{0}^{i}\right\}_{i \in[0, \chi]}$ be the same, but proportional costs of operating publicly traded firms be different with $\bar{\tau}>\underline{\tau}$. Then, in the economy with $\underline{\tau}$, entrepreneurs are worse off, while workers are better off.

The intuition for the results in Theorem 1 is straightforward. Both economies with $\underline{\tau}$ and $\bar{\tau}$ face the same world interest rate $R_{w}$. With an aggregate capital increase given in (8) and a constant labor supply, the capital-labor ratio and wages will be higher in the economy with low proportional cost $\underline{\tau}$. Since, in equilibrium, workers choose to consume all of their labor income in both economies, they will be strictly better off in the economy with $\underline{\tau}$.

Entrepreneurs face two returns: the return on investment in their own firms and the 
return on their public equity investment. With higher wages, the cost of labor hired by entrepreneurs in their own firms is higher and returns are lower in the $\underline{\tau}$ economy. At the same time, public equity returns do not differ across the two economies pinned down by the world interest rate. Thus with lower returns in their own firms, entrepreneurs face worse investment opportunities in the $\underline{\tau}$ economy and cannot be better off.

Alternatively, consider any allocation chosen by the entrepreneur in the economy with a low proportional cost, $\underline{\tau}$. This allocation would cost strictly less in the economy with a high equity cost $\bar{\tau}$ due to its lower price of labor. Entrepreneurs in the economy with a high public equity cost can improve on this allocation by increasing their consumption.

Theorem 1 implies that in the small open economy with $\bar{\tau}$, a reduction in the proportional cost to $\underline{\tau}$ would be associated with welfare losses of entrepreneurs and welfare gains of the workers.

Alternative scenarios for welfare effects. Unlike the case of the small open economy, when $g(\cdot)$ is an increasing function, the supply of capital at each interest rate is limited. Therefore, a reduction in the public equity cost from $\bar{\tau}$ to $\underline{\tau}$ increases both the demand for and the cost of capital. Other things equal, the capital-labor ratio and wages of the workers increase by less than in the case of the small open economy.

For entrepreneurs, a wage increase is associated with a reduction in returns in their own firms, but this reduction is smaller than in the case of the small open economy. At the same time, returns to public equity increase somewhat. When the elasticity of the interest rate is small, entrepreneurs would still be worse off. However, the loss in welfare would be smaller.

Welfare outcomes in the cross-section. The sign and magnitude of the welfare effects of entrepreneurs is independent of their position in the initial distribution due to homotheticity of preferences.

Quantitative results. To quantify the qualitative findings above, among other parameter values one needs to know: $(i)$ the variance of the productivity process in entrepreneurial firms, $\sigma_{\eta}^{2},(i i)$ the magnitude, $\epsilon$, of the plausible reduction in the proportional public eq- 
uity cost, and (iii) the shape of the foreign lending schedule. The estimates of $(i)-(i i i)$ are obtained from micro and macro data detailed in Sections 6,7 .

Recall that in the model, the stationary wealth distribution does not exist. Therefore, to obtain an accurate distribution of the welfare losses of entrepreneurs, one also needs an initial distribution of their wealth from the data. Section 8 provides details on the construction of the initial distribution in the model and summarizes all of the quantitative findings.

\section{Micro Estimation}

This section provides detailed information about the estimation of the factor income shares and the productivity process in the data.

\subsection{Description of the Data}

In the estimation, I use data from business sectors of Ecuador and Chile. They come from two sources: Ecuador's Manufacturing, Services and Retail Trade Survey, and Chile's Manufacturing Census. The Chilean data are well known and have been widely used in the development and industrial organization literatures. A full description of the data is available elsewhere ${ }^{19}$ therefore, only the necessary details will be repeated here. Data for Ecuador are relatively new and will be the focus of this section. ${ }^{20}$

Ecuador. Data for Ecuador come from the Instituto Nacional de Estadistica y Censos (INEC, National Institute of Statistics and Census). The data's collection by INEC has been mandated by law, and the first three representative sectoral samples for manufacturing, services and retail trade were compiled in 1995. For the purpose of comparability, I will use only the manufacturing sample.

The type of data is a survey with the company as the primary sampling unit. At first, the

\footnotetext{
$19 \operatorname{Liu}(1991)$ is the original source for the description of the data and the construction of all the variables.

${ }^{20}$ The data for Ecuador were used in earlier versions of Arellano, Bai, and Zhang (2012), which focused on the comparison of firm-level growth and financing patterns in Ecuador and the United Kingdom. Among other studies using these data is Cubas, Ho, Huyhn, and Jacho-Chavez (2012).
} 
sample included around 3,000 companies, a significant fraction of which have remained and continue their activities. Companies from the original sample that terminated operations were replaced by others with similar characteristics. At the same time, the new companies were added to the sample in a way that preserved its representative nature. In this unbalanced panel, the annual company data are available from 1995 to 2006.

The survey questionnaire poses detailed questions about the primary and secondary production activities of each company, including output produced, intermediate consumption and value added; capital stock; fixed and inventory investments; employment; total remuneration and its components in wages and contributions to social security for employees; number of owners of the firm; and so on ${ }^{21}$ All of the companies are registered with the authorities for tax purposes, and therefore the data used do not cover the informal sector of the economy. The sample includes both privately held and publicly traded companies. The capital share of publicly traded companies, however, constitutes a mere $3 \%$, which reflects the small size of public equity markets in Ecuador 22 About $2 / 3$ of the sample are corporations, limited-liability companies, and about 1/3 are general and limited partnerships.

To be consistent with Chilean data, I use only the manufacturing portion of the Ecuadorian survey, with about 1,500 manufacturing companies per year. Table 1 provides details on the sample selection process and Table 2 summarizes some descriptive statistics for the companies in the data set, for both countries. The variables from the survey used in the estimation include value added, net investment, employment and the capital stock.

To exploit the panel component of the data, the values of these variables have been converted into constant prices using the method of Liu (1991) originally applied to Chilean Manufacturing Census data, as described in Appendix B.

\footnotetext{
${ }^{21}$ Note that for the purposes of the model, it does not matter whether the non-publicly traded company has multiple owners. The main criterion is whether these ownership or equity shares are liquid and readily transferable. In the case of non-traded companies, they are not.

${ }^{22}$ Capital is reported at its end-of-period value, which includes inflationary adjustment. From the descriptions of the data, it is hard to determine whether it is reported at the true replacement cost. There is no variable with the traded status of the company. To determine which companies are traded, I match their identification numbers in the data set with the identification numbers for the publicly traded companies used by Ecuador's Superintendence of Companies, which keeps a registry of all publicly traded companies.
} 
Table 1:

Sample Selection for Ecuador and Chile

\begin{tabular}{lcc}
\hline & Ecuador & Chile \\
\hline Original sample & 6,860 & 12,916 \\
\hline Excluded & & \\
\hline Missing capital & 108 & 5,413 \\
\hline Missing labor & 9 & 0 \\
\hline Missing value added & 546 & 385 \\
\hline Missing investment & 3,106 & 7,145 \\
\hline Final sample & 3,376 & 3,405 \\
\hline
\end{tabular}

Chile. The Chilean data are collected annually by the Instituto Nacional de Estadisticas (INE). By design, the Census includes all of the manufacturing plants with at least 10 workers. ${ }^{23}$ Its data coverage is similar to Ecuador's Manufacturing Survey ${ }^{24}$

The plants in the sample belong to limited-liability companies, corporations, co-operatives, public enterprises and others. The capital share of plants owned by publicly traded companies is approximately 10 times that of Ecuador, or about $30 \% .25$

Given data limitations, I associate each plant with one company. On the one hand, this could be justified by using the data from the United States, where across all employer firms in 2002, the average number of plants per firm was 1.25, and across all firms 1.05. ${ }^{26}$ On the other hand, the estimates obtained in the plant-level data would represent an upper bound on the measure of idiosyncratic investment risk, given that risks associated with plants operating in different sectors could partially offset each other. For the purpose of measuring uncertainty faced by entrepreneurs, the available data are quite suitable. They would represent a substantially greater challenge for a modelling set-up discussed in the introduction, where risk sharing is endogenized, and the distinction between a plant and a

\footnotetext{
${ }^{23}$ There are plants in the sample that employ less than 10 workers as well.

${ }^{24}$ For details of the data coverage and construction of the variables, please see Liu (1991).

${ }^{25}$ These capital stocks are reported on the plants' balance sheets. I classify plants as publicly traded if they have a corporate form of organization and pay dividends in the current year (dividends here are associated with publicly traded companies, while other types of distributions characterize privately held companies). Then I average the share of publicly traded capital in total capital and report it in Table 2. The descriptive statistics for the plants in the aggregate are provided in Table 2.

${ }^{26}$ Source: Census Bureau, Statistics about Business Size, http://www.census.gov/epcd/www/smallbus.html.
} 
Table 2:

Aggregate Statistics for Ecuador and Chile based on Micro Data for 1995-2006

\begin{tabular}{lcc}
\hline Statistics & Chile & Ecuador \\
\hline Capital-value added ratio & 1.47 & 1.24 \\
\hline $\begin{array}{l}\text { Share of publicly traded } \\
\text { capital in total capital }\end{array}$ & 0.30 & 0.03 \\
\hline Depreciation rate, \% & 8.0 & 12.0 \\
\hline Investment rate, \% & 10.0 & 13.1 \\
\hline
\end{tabular}

firm is more meaningful.

\subsection{Estimation Procedure}

This section describes the estimation procedure for the factor income shares and parameters of the productivity process in the individual production technology of entrepreneurs. It is based on the proxy variable approach to production function estimation, which corrects for endogeneity in firm input choices and allows for time-varying heterogeneity. This approach was originally suggested by Olley and Pakes (1996, henceforth OP) and later modified by Levinsohn and Petrin (2003, henceforth LP). In what follows I will discuss its assumptions and the implementation in the context of the model. I will use the sample variance of the residuals from the production function estimation as a measure of productivity risk in entrepreneurial firms in the model.

Recall the structure of the entrepreneur's problem associated with the privately held firm. The capital of the firm in period $t, k_{t}$, is determined as part of the entrepreneurial portfolio choice at date $t-1$. It is a fixed input in the firm's production technology. Given $k_{t}$, the variable labor input, $n_{t}$, is chosen by the entrepreneur in response to the realization of an i.i.d. productivity shock $\eta_{t}$ at the start of period $t$. At $t$, the entrepreneur also decides how much to invest in a privately held firm for the next period. With the i.i.d. assumption, the expectation of future productivity is not affected by the current realization. Other things equal, investment depends on the current realization of productivity through its effect on the 
total resources of the entrepreneur. In particular, entrepreneurs with different realizations of current productivity choose to invest the same portfolio share in privately held firms.

This discussion can be translated into the following structural assumptions: $(i) k_{t}$ is a predetermined input in the production technology; $(i i) n_{t}=n\left(\eta_{t}, w_{t}\right) k_{t}$ is an endogenous input, and $\eta_{t}$ fully transmits into $n_{t} ;(i i i) k_{t}$ and $\eta_{t}$ are contemporaneously uncorrelated; $(i v)$ the current-period investment in the privately held firm is a monotone function of the current productivity shock, $\eta_{t}$. Both labor input in $(i i)$ and investment in the privately held firm in $(i v)$ respond to the realization of the productivity shock. However, unlike labor, investment does not enter the production function estimation. Then, the idea of the proxy variable approach is to use investment as a proxy for the realization of productivity to help identify the coefficient on the labor input. Assumption $(i v)$ is the key technical assumption which allows that to occur. It ensures that the investment function is invertible, so that investment serves as a perfect proxy for the productivity shock. This allows investment to be expressed as a function of observables. Lemma 4, Appendix A verifies that (iv) is satisfied in the model with respect to entrepreneurial investments in their privately held firms. More generally, assumptions $(i)-(i i)$ and $(i v)$ are the same as in OP, while assumption (iii) is a departure from the first-order Markov process that LP assume on productivity ${ }^{27}$ I modify the proxy variable approach appropriately to estimate the production function given assumption (iii). I next describe the approach and the modifications introduced.

Starting with the specification of the data-generating process in logged variables denoted with tildes, 28

$$
\tilde{y}_{t}=\beta_{0}+\beta_{k} \tilde{k}_{t}+\beta_{n} \tilde{n}_{t}+\tilde{\eta}_{t}+\tilde{u}_{t}, \tilde{\eta}_{t} \sim \mathrm{N}\left(0, \sigma_{\eta}^{2}\right), \text { and } \tilde{u}_{t} \sim \mathrm{N}\left(0, \sigma_{u}^{2}\right)
$$

where $\tilde{\eta}$ is the part of the shock transmitted to the firm's decision, and $\tilde{u}$ is the untransmitted

\footnotetext{
${ }^{27}$ With the first-order Markov process, capital $k_{t}$ would be correlated with the persistent part of the productivity, but uncorrelated with the current period's innovation.

${ }^{28} \mathrm{I}$ do not impose the constant-returns-to-scale assumption, and test it in the data post-estimation. I find that it is not rejected in the data with the proxy variable approach, but not with OLS, which gives inconsistent estimates of the coefficients when the labor input is endogenous.
} 
part (e.g., measurement error in output), the estimation proceeds in two stages. ${ }^{29}$

Stage 1: Using OLS, estimate the labor coefficient $\beta_{n}$ substituting for the productivity shock $\eta_{t}$ the inverse of the investment function.

Stage 2: Write down the partial productivity equation with the dependent variable $\tilde{y}_{t}-$ $\hat{\beta}_{n} \tilde{n}_{t}$ using the estimate of $\hat{\beta}_{n}$ from stage 1 and obtain a consistent estimate of $\hat{\beta}_{k}$ using OLS.

More specifically, for stage 1 of the estimation, the relationship between productivity, capital and investment in the model is given by

$$
i_{t}=k_{t}\left[\varsigma_{t}\left(\phi_{t} R_{k t} \eta_{t}+R_{t}\left(1-\phi_{t}\right)\right)-(1-\delta)\right]
$$

The right-hand side of (10) defines the investment function $i\left(k_{t}, \eta_{t}\right)$. It is continuous, and as shown in Lemma 4, Appendix A, is strictly increasing in $\eta_{t}$ for given $k_{t}{ }^{30}$ Therefore, function $i\left(k_{t}, \cdot\right)$ is invertible. In the estimation, I will use a general form of the investment function ${ }^{31}$ given by

$$
\tilde{\eta}_{t}=g\left(\tilde{k}_{t}, \tilde{i}_{t}\right)
$$

I substitute (11) into (9) and rewrite:

$$
\tilde{y}_{t}=\tilde{\beta}_{0}+\beta_{k} \tilde{k}_{t}+\beta_{n} \tilde{n}_{t}+g\left(\tilde{i}_{t}, \tilde{k}_{t}\right)+\tilde{u}_{t}
$$

Note that coefficient $\beta_{k}$ cannot be identified in 12 , since capital $k_{t}$ enters twice in $\beta_{k} \tilde{k}_{t}$ and $g\left(\tilde{i}_{t}, \tilde{k}_{t}\right)$. Thus, to obtain a consistent estimate of $\beta_{n}$, define

$$
\varphi\left(\tilde{i}_{t}, \tilde{k}_{t}\right) \equiv \tilde{\beta}_{0}+\beta_{k} \tilde{k}_{t}+g\left(\tilde{i}_{t}, \tilde{k}_{t}\right)
$$

\footnotetext{
${ }^{29}$ More recently, a number of papers, notably Wooldridge (2005) and Ackerberg, Caves, and Fraser (2005), have suggested alternative estimation procedures based on the ideas of OP and LP. In particular, Wooldridge suggests using a generalized method-of-moments estimation, as opposed to the two-step estimation approach used in both LP and OP, on the grounds of efficiency and potential problems with identification of the firststage coefficients in LP.

${ }^{30} i(\cdot, \cdot)$ is also a function of other variables in the model.

${ }^{31}$ It is also possible to determine whether the model is consistent with the data by testing a particular functional form; however, this will not be pursued at this point.
} 
Following OP, I use a low-order polynomial in $\tilde{i}$ and $\tilde{k}$ to approximate function (13):

$$
\varphi\left(\tilde{i}_{t}, \tilde{k}_{t}\right)=\sum_{l=0}^{3} \sum_{j=0}^{3-l} \delta_{l j} \tilde{i}_{t}^{l} \tilde{k}_{t}^{j}
$$

where $\delta_{00}$ is the constant term. This gives the estimable version of $(12)$, which is a function of observables only:

$$
\tilde{y}_{t}=\beta_{n} \tilde{n}_{t}+\sum_{l=0}^{3} \sum_{j=0}^{3-l} \delta_{i j} \tilde{i}_{t}^{l} \tilde{k}_{t}^{j}+\tilde{u}_{t} .
$$

Since $\tilde{u}_{t}$ is the component of productivity disturbance that does not transmit into any decisions of the firm (either $\tilde{n}_{t}, \tilde{k}_{t}$ or $\tilde{i}_{t}$ ), OLS provides unbiased and consistent estimates of $\beta_{n}$ and coefficients $\left\{\delta_{l j}\right\}$ of the $\varphi$ function. This completes stage 1 of the estimation.

Under the i.i.d. assumption on the shocks, one only needs coefficient $\hat{\beta}_{n}$ to write down the partial productivity equation in stage 2 . The dependent variable in this equation is the output net of labor's contribution, $\tilde{y}_{t}-\hat{\beta}_{n} \tilde{n}_{t}$, and the independent variable is capital ${ }^{32}$

$$
\tilde{y}_{t}-\hat{\beta}_{n} \tilde{n}_{t}=\beta_{k} \tilde{k}_{t}+\tilde{\eta}_{t}+\tilde{u}_{t}
$$

This equation can also be estimated using OLS, which gives consistent and unbiased estimates of $\beta_{k}$. This is the case, since $\tilde{k}$ and $\tilde{\eta}$ are contemporaneously uncorrelated and $\tilde{u}$ is an untransmitted component 33

Using $\hat{\beta}_{k}$ and $\hat{\beta}_{n}$ from the two-stage estimation, one can obtain consistent predictions of the sample residuals:

$$
\tilde{\eta}_{t}+\tilde{u}_{t} \equiv \tilde{y}_{t}-\hat{\beta}_{n} \tilde{n}_{t}-\hat{\beta}_{k} \tilde{k}_{t}
$$

The estimated sample variance of these residuals constitutes the measure of the productivity risk in the model.

\footnotetext{
${ }^{32}$ See Griliches and Mairesse (1995) for the discussion of this case.

${ }^{33}$ With a first-order Markov process assumed in OP, the partial productivity equation in the second stage is more complicated, taking into account productivity dynamics. In particular, the second-stage estimation also uses coefficients $\left\{\delta_{l j}\right\}$ from the approximation of the investment function to define the persistent component of productivity.
} 
Table 3:

Estimation Results

\begin{tabular}{ccccc}
\hline & \multicolumn{2}{c}{ Ecuador } & \multicolumn{2}{c}{ Chile } \\
\hline & OLS & Proxy & OLS & Proxy \\
\hline Capital & $0.30(.007)$ & $0.367(.105)$ & $0.29(.009)$ & $0.32(.158)$ \\
\hline Labor & $0.90(.016)$ & $0.69(.032)$ & $0.99(.015)$ & $0.67(.038)$ \\
\hline N obs. & 3376 & 3376 & 3405 & 3405 \\
\hline$\sigma^{2}$ & 0.73 & 0.66 \\
\hline
\end{tabular}

Table 3 summarizes the values of the estimated income shares and of the variance of productivity shocks for the benchmark parameterization of the model. OLS coefficients are included to illustrate biases introduced into the estimation when endogeneity of the labor decision in the firm's problem is ignored. The standard errors reported in the table are obtained using a bootstrap method for the two-stage estimation. This procedure closely follows LP.

Values for $\sigma^{2}$ reported in Table 3 for Chile and Ecuador suggest a lot of uncertainty associated with operating individual production technology in entrepreneurial firms. These values, however, cannot be compared directly to those available in the literature. They differ both in the data sources and in the assumptions underlying the method used. More importantly, given these differences, the values obtained elsewhere in the literature might not be used for the purposes of this paper either ${ }^{34}$ I address the departure from OP in assumption $($ iii $)$ on the productivity process and other caveats associated with the proposed estimation procedure in Appendices C and D.

\footnotetext{
${ }^{34}$ See, e.g., Davis, Haltiwanger, Jarmin, and Miranda $(2006)$, Campbell, Lettau, Malkiel, and Xu (2001), and others. Davis, Haltiwanger, Jarmin, and Miranda (2006) compute measures of volatility and dispersion of the employment and sales growth rates of publicly traded and privately held firms. Dispersion reflects year-to-year between-firm variation in growth rates, whereas volatility refers to within-firm variation. The employment-weighted standard deviation of privately held firm growth rates is reported between 0.6 and 0.85. The issue of using the estimates available in the literature in specific models is more general, since the match between parameter estimates in the literature and the model's input requirements seldom exists.
} 
Table 4: Distribution of Capital across Companies in Ecuador's Manufacturing Survey (2003), fraction of total capital

\begin{tabular}{ccccccccccc}
\hline Decile & 1 & 2 & 3 & 4 & 5 & 6 & 7 & 8 & 9 & 10 \\
\hline \% owned & 0.1 & 0.2 & 0.4 & 0.7 & 1.3 & 2.4 & 3.2 & 5.5 & 14.5 & 70.6 \\
\hline
\end{tabular}

\subsection{Distribution of Capital of Entrepreneurial Firms}

Recall from Section 5 that the sign of the welfare effects on entrepreneurs from a reduction in proportional public equity costs does not depend on their position in the initial distribution. The initial wealth level matters only for the size of the welfare effects. Since the model does not deliver a stationary distribution in the cross-section, an initial distribution for the experiment can be defined by its empirical counterpart. This would allow for a more accurate assessment of welfare outcomes of entrepreneurs.

For Ecuador, the empirical distribution is obtained using data from the Manufacturing Survey. Table 4 reports the fraction of capital owned by the companies in each decile of the distribution. Using relationships in the model, the distribution of capital of these companies can be used to obtain the initial wealth distribution of entrepreneurs. The distribution of capital in the data and the resulting distribution of wealth used in the model exhibit high concentrations in their upper tails.

\section{Parameterization}

This section summarizes all the choices of the functional form and parameter values in the model, including those estimated in the micro data directly in Section 6.

Preferences: $\gamma, \beta$. Preferences are assumed to be of standard CRRA form In the benchmark parameterization, $\gamma$ is set to 1 with a logarithmic period utility of workers and entrepreneurs. The discount factor for both workers and entrepreneurs $\beta$ is set to $0.95 .^{36}$

\footnotetext{
${ }^{35}$ The assumption of Epstein-Zin preferences would not affect the qualitative findings in this paper. At the same time, this preference specification would require additional parameter values. They would have to be taken from the literature, since the data available do not allow them to be estimated directly.

${ }^{36}$ Assuming a growth rate for the economy of $2.2 \%$, and taking the standard value of $\beta=0.98$, the
} 
Table 5:

Benchmark Parameterization

\begin{tabular}{|c|c|c|c|}
\hline & Ecuador & Chile & Source \\
\hline \multicolumn{4}{|c|}{ Parameters that do not matter quantitatively } \\
\hline$\gamma$ & 1 & 1 & Range \\
\hline$\beta$ & 0.95 & 0.95 & Range \\
\hline$\delta$ & 0.12 & 0.08 & INEC-Ecuador \& INE-Chile \\
\hline$\psi$ & {$[0.004,0.017]$} & {$[0.004,0.017]$} & BIS \\
\hline$\chi$ & 0.30 & 0.24 & ILO, employment status survey \\
\hline$R_{w}$ & 1.026 & 1.026 & Average lending rate \\
\hline \multicolumn{4}{|c|}{ Parameters that matter quantitatively } \\
\hline$\alpha$ & 0.36 & 0.32 & INEC-Ecuador \& INE-Chile \\
\hline$\sigma_{\eta}^{2}$ & 0.73 & 0.66 & INEC-Ecuador \& INE-Chile \\
\hline$\tau$ & 0.12 & 0.10 & $\begin{array}{l}\text { Target publicly traded } \\
\text { Capital share, } \kappa\end{array}$ \\
\hline
\end{tabular}

I perform a sensitivity analysis with respect to both of these parameters, for a range of acceptable values.

Technology and shocks: $\alpha, \sigma_{\eta}^{2}$, and $\delta$. Using previously obtained estimates from Table 3 , the share of capital in the individual and aggregate production technology $\alpha$ is set at 0.36 for Ecuador and 0.32 for Chile. The variance $\sigma_{\eta}^{2}$ parameterizes the distribution of the productivity shocks, and it is taken as 0.73 for Ecuador and 0.66 for Chile. The depreciation rates of physical capital are set to their estimated values of 0.12 and 0.08 for Ecuador and Chile, respectively.

Foreign bank lending schedule. Choosing a specific functional form, the lending schedule in Section 3.5 for $B<0$ is set to be a function of $R_{w}$ and $\psi$ :

$$
\left.g\left(\left|\frac{B}{Y}\right|\right\}\right)=R_{w}+\left(\exp \left(\psi\left|\frac{B}{Y}\right|\right)-1\right)
$$

The parameter of interest here is $\psi$. I choose the range of values of $\psi$ between 0.004 and 0.015. This range includes estimates from the Bank for International Settlements Altunbas and Gadanecz (2003) ) obtained in the regression of log of drawn fees on macroeconomic and "detrended" value of $\beta$ is given by $\frac{0.98}{(1+0.02)^{1}} \approx 0.95$. 
microeconomic variables ${ }^{37}$ In particular, the coefficient on the aggregate debt-to-GDP ratio from this regression is reported to be positive and statistically significant with the point estimate of 0.00838 I take an interval around this estimate and do robustness checks. For the base rate $R_{w}$, I take the sum of the average lending spread and fees for manufacturing loans and the average LIBOR for the period 2000-05.39 It is standard practice to price international loans off LIBOR as a proxy for the cost of funds for the banks themselves. I also choose other values of $R_{w}$ to check the sensitivity of the quantitative findings.

Population structure: $\chi$. I experiment with several parameter values for the share of entrepreneurs $\chi$. The benchmark values are set to 0.30 for Ecuador, and 0.24 for Chile from the International Labour Organization (ILO) survey of employment, by status in employment and industry. These values represent reported self-employment status in manufacturing. As defined by the ILO, this category includes all employed whose remuneration directly depends upon profits (or the potential for profits) derived from the goods and services produced. This definition is consistent with the notion of an entrepreneur in the model economy. For both Ecuador and Chile, the self-employed category includes employers (self-employed who employ workers on a continuous basis) and own-account workers (self-employed who do not employ workers on a continuous basis). For robustness, I use the fractions of employers alone. These numbers are smaller: $3.2 \%$ for Chile and $2.0 \%$ for Ecuador 40 More generally, the fractions of self-employed in the population across all sectors in Ecuador and Chile are equal to 0.36 and 0.29 , respectively.

Time endowment: $\nu$. In Sections 3.1 and 3.2 and in the benchmark parameterization, the time endowments of entrepreneurs and workers are set to 0 and 1, respectively. More

\footnotetext{
37 Altunbaş and Gadanecz (2003) consider a sample of 5,000-plus loans to developing countries and estimate their econometric model on this sample. They do not report the results by sector, but, together, the manufacturing and financial sectors account for a large fraction of these loans.

${ }^{38} \mathrm{~A}$ positive sign means that higher fees are associated with higher debt-to-income ratios.

${ }^{39}$ Reported by Altunbaş and Gadanecz (2003).

${ }^{40}$ For the United States, the fraction of entrepreneurs varies across studies according to different definitions. In particular, it depends on the minimum amount of equity participation and the management role in the business. This fraction is commonly reported between $9 \%$ and $12 \%$. Entrepreneurs who operate their businesses in manufacturing constitute about $6 \%$, based on the data from the Federal Reserve's Survey of Consumer Finances between 1989 and 2007.
} 
generally, one could use a range of values for the time endowment of entrepreneurs, $\nu \in[0,1]$. With $\nu>0$, entrepreneurs have an additional source of income, which enters the right-hand side of their budget constraint. The general form of this budget constraint is given by

$$
c_{t}+k_{t+1}+b_{t+1}+x_{t+1} \leq \pi_{t}+R_{t} b_{t}+R_{x t} x_{t}+\nu w_{t} .
$$

In terms of the welfare effects, with positive time endowment, entrepreneurs would also be able to benefit from higher wages. The overall effect for entrepreneurs in this case is the net of the welfare gains associated with higher wages and the losses associated with changes in entrepreneurial returns $\stackrel{41}{4}$ Using different values of their time endowment $\nu$, entrepreneurs would still experience a net welfare loss, as shown in Section 8.3. In other words, the welfare loss is non-decreasing in the time endowment of the entrepreneur.

Public equity share: $1-\kappa$. I use the values reported previously in Table 2 with public equity shares set to 0.03 and 0.30 for Ecuador and Chile, respectively. They are used in estimating the cost $\tau$ of operating publicly traded companies, discussed next.

Proportional public equity cost: $\tau$. Recall that costs associated with operating a publicly traded firm are proportional to the scale of operation, with the proportion given by $\tau$. They are broadly defined to include transaction, information and enforcement costs. Accurate direct measures of these costs in the data are not available. The direct component is arguably also rather small, so that a sizable part of the costs would require an indirect measurement in the data. As a result, in the model $\tau$ is set to match the share of publicly traded capital in the total capital, $\kappa$. I also perform an additional check on the value of $\tau$ obtained from the model. In particular, recall the equilibrium relationship between the safe returns in the model:

$$
R=\frac{F_{K}+1-\delta}{1+\tau}
$$

where $F_{K}$ refers to the marginal product of aggregate capital in the entrepreneurial sector,

\footnotetext{
${ }^{41}$ Recall that changes in wages and returns have the opposite sign, with the percentage change in wages smaller than in returns.
} 
and $R$ refers to the safe return to public equity and interest on foreign assets. Then, by simply substituting out,

$$
1+\tau=\frac{F_{K}+1-\delta}{R}
$$

In the data, I construct an interval for $\tau\left[\tau_{\text {low }}, \tau_{\text {high }}\right]$, where the end points of the interval are computed using two different "safe" rates of return $R{ }^{42}$ Given the inverse relationship between $\tau$ and $R$, I use the stock market returns in the manufacturing sector for $\tau_{\text {low }}$ and LIBOR for $\tau_{\text {high }}{ }^{43}$ For Chile, the stock market return is set to the return earned on the Chile BEC Industrials Index; for Ecuador, it is set to the Quito Stock Exchange Industrials Index ${ }_{4}^{44}$ The value of $F_{k}$ is constructed as the marginal product of aggregate capital of the privately held firms in the estimation sample in Section $6.2^{45}$ I verify that the value of $\tau$ obtained using $(i)$ in the model falls in the interval $\left[\tau_{\text {low }}, \tau_{\text {high }}\right]$. For Ecuador, $\tau$ is set to 0.12 in the interval [0.035, 0.138], and for Chile $\tau$ is set to 0.10 in the interval [0.068, 0.237]. Using previously introduced notation, the low value of public equity cost for Chile will be denoted as $\underline{\tau}$, and for Ecuador $\bar{\tau}$.

\footnotetext{
${ }^{42}$ Safe here is defined in terms of the model.

${ }^{43}$ As an alternative to the stock market returns, I use the time deposit rate in commercial banks as calculated by each country's central bank. These rates come from the World Bank's Global Financial Dataset.

${ }^{44}$ Source: The World Bank's Global Financial Dataset. BEC stands for Bolsa Electronica de Chile (Chilean Electronic Exchange). The broad definition of "Industrials" includes capital goods and commercial services producers in sectors such as aerospace and defense; building products; construction and engineering; electrical equipment; industrial conglomerates; machinery; trading companies and distributors; and commercial printing. Over the period 1995-2006, the Chilean BEC Index, on average, yielded 17.02\%. At the same time, Ecuador's industrials index earned $5.03 \%$ over the period 1995-2002, for which the data are available.

${ }^{45} \mathrm{I}$ use capital and value added aggregated in the micro sample for each country and the estimated coefficient $\hat{\beta}_{k}$ to get:

$$
F_{K t}=\hat{\beta}_{k} \frac{Y_{t}}{K_{t}} .
$$

I then average these returns across the years available. For Ecuador, the value of $F_{K}$ is $27 \%$, and for Chile it is $33 \%$, both net.
} 


\section{Quantitative Results}

\subsection{Model and Data}

With parameterization from Table 5 , Table 6 reports the comparison between the steadystate values of ratios generated by the model and those in the data. The model matches capital-to-output and investment-to-output ratios from aggregated micro data reasonably well, when $\tau$ is calibrated to match the fraction of aggregate capital in the publicly traded sector. The next subsection reports quantitative findings from the counterfactual experiment of reduction in public equity costs performed in this calibrated framework.

Table 6: Model and data: steady-state comparison

\begin{tabular}{lcccc}
\hline & \multicolumn{2}{c}{ Ecuador } & \multicolumn{2}{c}{ Chile } \\
\hline & Model & Data & Model & Data \\
\hline Capital-output ratio & 1.24 & 1.29 & 1.47 & 1.446 \\
\hline Investment-output ratio & 0.1309 & 0.1557 & 0.10 & 0.1157 \\
\hline
\end{tabular}

\subsection{Counterfactual Experiment}

Consider the following counterfactual experiment of reducing the proportional cost $\tau$ of operating a publicly traded firm. Start with the steady state of Ecuador's economy with a high proportional cost $\tau=\bar{\tau}$. Let $\bar{\tau}$ in Ecuador decrease overnight to its Chilean level, $\bar{\tau}$. Follow the path of Ecuador's economy with $\underline{\tau}$ to its new steady state, and assess associated changes in the aggregates and individual welfare of workers and entrepreneurs.

\subsection{Quantitative Assessment of the Experiment}

The quantitative results in this section are reported for the overnight reduction in public equity costs in Ecuador of approximately $15 \%$ (i.e., from 0.12 to 0.10 ). In terms of the aggregate dynamics, in the period after this reduction the aggregate capital stock, wages, output and the debt-to-income ratio all increase, and converge slowly from above to their 
new steady-state values. In particular, in the long run the capital stock increases by $5.4 \%$, and the corresponding increase in output is approximately $1.9 \%$. This is also the magnitude of the permanent increase in output per capita. Given the observed gap in income levels in the two countries, this increase can be considered rather small. The same conclusion applies to the contribution of the gap in financial development (proportional public equity costs) to income differences more generally. In terms of the effects on prices, a reduction in public equity costs increases the wages of the workers by about $1.9 \%$. This increase in wages leads to the ratio between the new and the old returns of entrepreneurs in their privately held firms of 0.968 .

These aggregate effects in turn translate into the following welfare outcomes. Assuming the same level of wealth, a reduction in public equity costs is associated with the welfare loss of entrepreneurs of about $9.9 \%$ in lifetime consumption equivalents. At the same time, the gain for the workers constitutes about $3.2 \%$ in lifetime consumption equivalents. More generally, the welfare loss of entrepreneurs depends on their initial wealth level. Since the model does not deliver a stationary distribution in the cross-section, to provide an accurate assessment of the welfare outcomes of entrepreneurs, I use the empirical distribution constructed in Section 6.3.

The distribution of capital in the data is very concentrated. I aggregate capital holdings of entrepreneurs into three levels for the initial distribution in the model. Deciles 1-7 of the empirical distribution form group 1, deciles 8-9 form group 2, and decile 10 forms group 3. The resulting initial distribution of capital is reported in Table 7. The welfare outcomes are inversely related to the initial holdings of capital. The entrepreneurs with smaller capital holdings experience larger welfare losses due to the increased cost of labor. The interpretation of the magnitude of these welfare effects might be subjective. However, the sign of the effects would unambiguously suggest caution on the part of entrepreneurs regarding any changes in public equity markets that could lead to a reduction in returns to their privately held firms. To be implemented, any policy changes that lead to a reduction in $\tau$ may require, as a result, 


\section{Table 7: Distribution of Capital and Welfare Losses of Entrepreneurs}

\begin{tabular}{lccc}
\hline Group $i$ & 1 & 2 & 3 \\
\hline Fraction of entrepreneurs & 0.7 & 0.2 & 0.1 \\
\hline Fraction of capital owned in the total & 0.084 & 0.21 & 0.706 \\
\hline
\end{tabular}

additional measures of compensation of entrepreneurs at least in part for the loss in their welfare, particularly for those with smaller capital holdings. These measures, for example, may involve lump-sum taxes or proportional taxes on the labor income of the workers, and lump-sum transfers to entrepreneurs.

The comparative statics with respect to other parameters in the model suggest that entrepreneurial welfare losses are non-increasing in parameter $\psi$ in the foreign interest rate schedule and in the amount of entrepreneurial risk $\sigma_{\eta}^{2}$. More generally, it might be interesting to quantify the effects of cross-country differences in the values of these parameters as well.

\section{Conclusions and Discussion}

Cross-country and panel regressions have contributed to our understanding of the relationship between financial and economic development by providing a broad set of correlations between the two. The regression approach, however, does not distinguish between different sources of financial development and does not quantify their contributions. It also cannot determine related distributional effects. Other approaches in the literature that have been better suited for these purposes include microeconomic studies and quantifiable economic models.

Some microeconomic studies have directly tested the mechanisms suggested by the theory using the industry/company/plant-level data. Unlike microeconomic studies, the economic modelling approach relates primitives, such as preferences, technologies, and so on, and policies to quantifiable predictions. It allows one to conduct controlled experiments where natural experiments are either unavailable or few. This paper uses an explicit economic 
model to design an experiment of exogenous reduction in public equity costs, and evaluates its quantitative aggregate and distributional impact. It determines the magnitude of this exogenous reduction by choosing two sets of parameter values, one to match the economy of Chile with low public equity costs, and another to match the economy of Ecuador, where public equity costs are high. In this way, the reduction in public equity costs in Ecuador is disciplined, and its effects on the aggregates and individual welfare can be evaluated.

A reduction in public equity costs produces differential welfare effects for workers and entrepreneurs. Entrepreneurs who would have been expected to benefit from this reduction are actually made worse off, while the workers are better off. The increase in aggregate output associated with these distributional effects is consistent with statistical relationships established in the regression analyses, but they overlook the distributional effects. Treating Ecuador and Chile as representative of the countries with different levels of financial development, this experiment might be of interest to policy-makers more broadly.

Several points should be noted with respect to the modelling choices made in the paper. First, the mechanism that generates welfare losses of entrepreneurs through equalization of wages between privately held and publicly traded sectors is rather simple, and the results are not unexpected given the set-up. The simplicity of the mechanism highlights the wage channel and avoids confounding it with other channels in alternative set-ups. Among others, entrepreneurs' arrangements to diversify risks related to their own firms could translate into less-stark outcomes when introduced into the model. These alternatives are not considered in the paper, and would be a subject of further research. Second, alternative treatments could be suggested for the two features that currently are part of the model: (i) the fixed split between entrepreneurs and workers and (ii) the assumption that the productivity shocks of entrepreneurs are i.i.d. over time. In the first case, a model of occupational choice would be required, but at this point it is not clear whether this complication is even desirable. In the second case, alternative formulations of entrepreneurial shocks over time are possible, e.g. with a fully persistent component embedded in an entrepreneurial type and an idiosyncratic 
component. Alternatively, one could introduce a process for firm-specific productivity shocks with a persistence parameter estimated in the data. Tests of the degree of persistence of productivity shocks based on the firm-level data for Ecuador suggest that it is relatively low, and the persistent part of the process could be ignored at least for the case of that country ${ }^{46}$ Generally speaking, the inclusion of alternative productivity processes would be more appropriate in the model with other features discussed above relative to the simple model presented in this paper, and is left for future research. Finally, the paper also leaves out any mapping between changes in parameter $\tau$ in the model and the types of policies that could be responsible for them. This renders the experiment conducted in the paper as an illustration, rather than a concrete plan of action with respect to the choice between different policies aimed at reducing the cost of companies' operation in public equity markets.

\footnotetext{
${ }^{46}$ Ábrahám and White (2006) find that the persistence of plant-level shocks in the U.S. manufacturing sector is also surprisingly low, with an average autocorrelation of the plant-specific productivity shocks of only 0.37 to 0.41 on an annual basis. In their study of the properties of risk associated with income generated by owners in their privately held businesses, DeBacker, Heim, Panousi, Ramnath, and Vidangos (2012), using tax panel data for the United States, show that business income is less persistent compared to labor income, with higher probabilities of extreme upward transition, in particular.
} 


\section{A Proofs}

Lemmas 1-4 are auxiliary, used in different stages of the characterization and not formulated as separate results in the body of the paper. Lemmas 1-2 are restated as in Angeletos (2007) with no proofs provided for space considerations. The proofs are identical to those of the paper cited. Proofs are provided for Theorem 1 and Lemmas 3-4 referred to in the text.

Lemma 1. Under the assumption of constant returns to scale:

$$
n_{t}=n\left(\eta_{t}, w_{t}\right) k_{t} \text { and } \pi_{t}=\left(R_{k}\left(\eta_{t}, w_{t}\right)+1-\delta\right) k_{t}
$$

where $n(\eta, w)=\arg \max _{l}[F(\eta, 1, l)-w l], R_{k}(\eta, w)=\max _{l}[F(\eta, 1, l)-w l]$ are labor input and profit per unit of capital, respectively.

Lemma 2. Given prices, optimal consumption, investment in private equity and the total of public equity investment and bond holdings are linear in wealth:

$$
c_{t}=\left(1-\varsigma_{t}\right) \omega_{t}, k_{t+1}=\varsigma_{t} \phi_{t} \omega_{t}, \bar{b}_{t+1} \equiv b_{t+1}+x_{t+1}=\varsigma_{t}\left(1-\phi_{t}\right) \omega_{t}
$$

where $\varsigma_{t}$ is the savings rate, and $\phi_{t}$ and $1-\phi_{t}$ are portfolio shares of risky and risk-free assets defined by

$$
\begin{gathered}
\phi_{t}=\arg \max _{\varphi \in[0,1]} E_{t}\left[\varphi_{t} R_{k}\left(\eta_{t+1}, w_{t+1}\right)+\left(1-\varphi_{t}\right) R_{t+1}\right]^{1-\gamma} \\
\rho_{t} \equiv E_{t}\left[\phi_{t} R_{k}\left(\eta_{t+1}, w_{t+1}\right)+\left(1-\phi_{t}\right) R_{t+1}\right]^{1-\gamma} \\
\left(1-\varsigma_{t}\right)^{-1}=1+\beta^{\frac{1}{\gamma}} \rho_{t}^{\frac{1}{\gamma}}\left(1-\varsigma_{t+1}\right)^{-1}
\end{gathered}
$$

Theorem 1. Consider two economies with the same vector of parameter values of technology $\{\alpha, \delta\}$ facing the world interest rate. Let the initial distribution of wealth of en-

trepreneurs $\left\{k_{0}^{i}, \bar{b}_{0}^{i}\right\}_{i \in[0, \chi]}$ be the same, but proportional costs of operating publicly traded firms be different with $\bar{\tau}>\underline{\tau}$. Then, in the economy with $\underline{\tau}$, entrepreneurs are worse off, while 
workers are better off.

Proof:

Recall the entrepreneurial budget constraint:

$$
c_{t}+k_{t+1}+\left(b_{t+1}+x_{t+1}(1+\tau)\right) \leq \eta_{t}\left(k_{t}\right)^{\alpha}\left(n_{t}\left(\eta_{t}\right)\right)^{1-\alpha}-w_{t} n_{t}\left(\eta_{t}\right)+R_{b t} b_{t}+x_{t} R_{x t},
$$

where $R_{x t}=\frac{\alpha X_{t}^{\alpha-1} L^{1-\alpha}}{1+\tau}$, and $R_{b t}=R_{w}$ in the case of the small open economy, and define

$$
\omega_{t} \equiv \eta_{t}\left(k_{t}\right)^{\alpha}\left(n_{t}\left(\eta_{t}\right)\right)^{1-\alpha}-w_{t} n_{t}\left(\eta_{t}\right)+R_{b t} b_{t}+x_{t} R_{x t}
$$

The decision rules of the entrepreneur are given by

$$
c_{t}=\left(1-\varsigma_{t}\right) \omega_{t}, k_{t+1}=\varsigma_{t} \phi_{t} \omega_{t}, \bar{b}_{t+1} \equiv b_{t+1}+(1+\tau) x_{t+1}=\varsigma_{t}\left(1-\phi_{t}\right) \omega_{t}
$$

where $\varsigma_{t}$ is the savings rate out of the total resources of entrepreneur $\omega_{t}$, and $\phi_{t}$ and $1-$ $\phi_{t}$ are portfolio shares of private equity and safe investments in public equity and bonds, respectively.

At date 0 , since $\left\{x_{0}^{i}, k_{0}^{i}, b_{0}^{i}\right\}_{i \in[0, \chi]}$ are the same, so are $X_{0}, K_{0}$ and $B_{0}$.

With a population of size 1 , the capital-labor ratio in both economies at date 0 is the same, and so are wages $w_{0}$, and $R_{x 0}$. Therefore, date 0 total resources of entrepreneurs with the same realization of the shock $\eta_{0}^{i},\left\{\omega_{0}^{i}\right\}_{i \in[0, \chi]}$ would be the same.

Consider an economy with low public equity cost $\underline{\tau}$. Let $\left\{c_{t}^{i}, k_{t+1}^{i}, \bar{b}_{t+1}^{i}\right\}_{t=0}^{\infty}$ be a sequence chosen by individual $i$, which satisfies the individual's budget feasibility and provides the maximum utility level given the initial resources $\left\{\omega_{0}^{i}\right\}$.

For both economies, it must be true that $\forall t>0$ :

$$
R_{w}=\frac{F_{K t+1}+1-\delta}{1+\tau}=\frac{R_{x t+1}+1-\delta}{1+\tau}
$$


with $\underline{\tau}<\bar{\tau}$, and a constant world interest rate for each $t>0: F_{K t+1}(\underline{\tau})>F_{K t+1}(\bar{\tau})$. This implies that for each $t>0, w_{t}(\bar{\tau})<w_{t}(\underline{\tau})$.

With $\left\{w_{t}(\bar{\tau})\right\}_{t=0}^{\infty}<\left\{w_{t}(\underline{\tau})\right\}_{t=0}^{\infty}$, and the same initial distribution $\left\{k_{0}^{i}, x_{0}^{i}, b_{0}^{i}\right\}_{i \in[0, \chi]}$, it must be true that the sequence chosen by entrepreneur $i$ in the economy with a low public equity cost $\underline{\tau}$ would cost strictly more than in the economy with a high public equity cost $\bar{\tau}$ due to higher wages. Therefore, the budget constraint of the entrepreneur in the economy with a high public equity cost will be slack, and extra available resources can be used to increase the consumption of the entrepreneur in the economy with a high public equity cost.

Thus, the entrepreneur in the high public equity cost economy can improve on the sequence of the entrepreneur in the economy with low public equity, and must be better off.

Lemma 3. Assuming that the steady state exists, a vector of parameters $\left\{\alpha, \sigma_{\eta}^{2}, R_{w}, \psi, \beta, \gamma, \chi\right\}$ of technology, foreign bond supply curve, preferences and population structure uniquely determines the aggregate steady-state quantities and prices as a function of the public equity $\operatorname{cost} \tau$.

Proof. Let $\lambda=\left\{\alpha, \sigma_{\eta}^{2}, \mathrm{R}_{\mathrm{w}}, \psi, \beta, \gamma, \chi\right\}$.

Determination of the steady-state equilibrium:

(i) For given values of parameters, the safe interest rate in the steady state of the open economy $R$ and the portfolio share of private equity, $\phi$, are uniquely determined by the system:

$$
\begin{gathered}
E_{\eta}\left(\frac{\eta}{\bar{\eta}} \phi R_{K}+(1-\phi) R\right)^{-\gamma}\left(\frac{\eta}{\bar{\eta}} R_{K}-R\right)=0 \\
\varsigma\left(\phi R_{K}+(1-\phi) R\right)=1,
\end{gathered}
$$

where $\varsigma=\beta^{\frac{1}{\gamma}} \rho^{\frac{1}{\gamma}}$ and $\rho \equiv E\left(\frac{\eta}{\bar{\eta}} \phi R_{K}+(1-\phi) R\right)^{1-\gamma}$.

With $R_{K}=R(1+\tau)$, equation (22) defines $\phi$ as a function of $R$ given $\lambda, \phi(R ; \lambda)$. Substituting $\phi(R ; \lambda)$, equation $(23)$ is a function of $R$ only given $\lambda$. 
(ii) Given parameters of the bond supply curve $\left(R_{w}, \psi\right)$, the ratio of the net foreign asset-to-income, $\frac{B}{Y}$, is determined by

$$
R=R_{w}+\left(\exp \left\{\psi\left|\frac{B_{t}}{Y_{t}}\right|\right\}-1\right)
$$

This result follows from the equilibrium condition that values $\left(R, \frac{\mathrm{B}}{\mathrm{Y}}\right)$ must be on the foreign bond supply curve.

(iii) For given values of technological parameters in $\lambda$, and $R$ from $(i)$, the steady-state wages, labor-capital ratio, and return to aggregate private equity are given by

$$
\begin{gathered}
n w=n w(R ; \lambda)=\left(\frac{R(1+\tau)-1+\delta}{\bar{\eta} \alpha}\right)^{\frac{1}{1-\alpha}} \\
w=w(R ; \lambda)=(1-\alpha)\left(\frac{R(1+\tau)-1+\delta}{\bar{\eta} \alpha}\right)^{\frac{-\alpha}{1-\alpha}} \\
R_{K}=R_{K}(R ; \lambda)=R(1+\tau),
\end{gathered}
$$

where $\bar{\eta}=\int_{\eta} \eta^{\frac{1}{\alpha}} g(\eta) d \eta$.

This result follows from the fact that, in equilibrium, returns to riskless foreign bonds and riskless public equity must be the same.

(iv) The steady-state capital stocks $X, K$ and the fraction of aggregate capital allocated to the publicly traded sector, $1-\kappa=\frac{X}{K+X}$, are uniquely determined by the system:

$$
\begin{gathered}
K+X=n w^{-1} \\
\frac{K}{X+B}=\frac{\phi}{1-\phi} .
\end{gathered}
$$

Equations (24)-(25) are the system of two linear equations in two unknowns, $K$ and $X$. Thus, its solution is unique, and so is the value of $\kappa=\frac{K}{K+X}$.

Lemma 4. Investment of entrepreneurs in their privately held firms is an increasing 
function of the realization of the productivity shock.

Proof:

Recall that investment in the entrepreneurial firm is given by

$$
i_{t}=k_{t+1}-(1-\delta) k_{t} \text {, where } k_{t+1}=\phi_{t} \varsigma_{t} \omega_{t} .
$$

Substituting for $k_{t+1}$ and simplifying:

$$
\begin{gathered}
i_{t}=\phi_{t} \varsigma_{t}\left(R_{k t}\left(\eta_{t}, w_{t}\right) k_{t}+R_{t}\left(b_{t}+x_{t}\right)\right)-(1-\delta) k_{t}=\phi_{t} \varsigma_{t}\left(R_{k t} \eta_{t} k_{t}+R_{t} \frac{1-\phi_{t}}{\phi_{t}} k_{t}\right)-(1-\delta) k_{t}= \\
\varsigma_{t} k_{t}\left(\phi_{t} R_{k t} \eta_{t}+R_{t}\left(1-\phi_{t}\right)-(1-\delta) k_{t}=k_{t}\left(\varsigma_{t}\left(\phi_{t} R_{k t} \eta_{t}+R_{t}\left(1-\phi_{t}\right)-(1-\delta)\right)\right.\right. \\
i_{t}=k_{t}\left[\varsigma_{t}\left(\phi_{t} R_{k t} \eta_{t}+R_{t}\left(1-\phi_{t}\right)\right)-(1-\delta)\right] .
\end{gathered}
$$

The right-hand side of (26) defines investment function $i\left(k_{t}, \eta_{t}\right)$. It is continuous and strictly increasing in $\eta_{t}$ for given $k_{t}$. Therefore, function $i\left(k_{t}, \cdot\right)$ is invertible:

$$
\eta_{t}=\frac{1}{R_{k t} \phi_{t}}\left(\left[\frac{i_{t}}{k_{t}}+1-\delta\right] \frac{1}{\varsigma_{t}}-\left(1-\phi_{t}\right) R_{t}\right) .
$$

\section{B Variables Construction}

To exploit in estimation the panel structure of the data, the values of the variables in current prices need to be converted into constant prices. For this purpose, I follow the deflation procedure using the aggregate price indices suggested by Liu (1991) as applied to the data from the Chilean Manufacturing Census.

\section{Variables in current prices}

At the firm level, output in current prices $=$ production of items for sale $(+)$ resale without processing $(-)$ cost of resales $(+)$ income from other activities and services $(+)$ production of assets for own use $(+)$ change in inventories of goods in process (end-of-period 
minus beginning-of-period value).

Intermediate consumption in current prices $=$ primary goods and auxiliary materials $(+)$ main operating and production costs (cost of goods sold plus operating and other administrative expenditures) $(+)$ other operating and production costs.

Then, value added in current prices $=$ nominal output in current prices - intermediate consumption in current prices.

Value of the capital stock $=$ machines and equipment $(+)$ buildings and structures $(+)$ transport $(+)$ office equipment $(+)$ other capital goods.

Gross investment for each capital asset is constructed as the value of new and used investment net of the value of assets sold in current prices (including replacement of depreciated assets).

\section{Variables in constant prices}

The values of variables in constant prices have been constructed using aggregate deflators from the input-output tables. The input-output tables use the two-digit sectoral classification of the system of national accounts (SNA). The firms in the data set report their industry according to the International Standard Industrial Classification (ISIC). I use concordance tables from the National Bank of Ecuador to map the ISIC to the SNA classification.

First, a deflator for each two-digit sector $j$ in the SNA is constructed as the ratio of the

value of gross output of the sector in current basic prices to its reported value in constant prices (with year 1995 as the base year):

$$
p_{j}=\frac{\text { gross output in current basic prices }}{\text { gross output in base year constant prices }} .
$$

Then, the value of output in the current prices of each firm is divided by the corresponding output deflator to get the output in constant prices.

The construction of the intermediate consumption deflators for the two-digit sectors is more involved. I first construct expenditure shares, $s_{i j}$, for each two-digit sector $i$. More 
specifically, sector $i$ 's expenditure share on input of sector $j$ is given by the ratio of its expenditure on input from sector $j$ to the total expenditure on intermediate consumption of sector $i$ :

$$
s_{i j}=\frac{\text { total expenditure on input from sector } j}{\text { total expenditure on intermediate consumption of sector } i} .
$$

The intermediate consumption deflator for the SNA industry $i, i c_{i}$, is constructed as the sum of the gross output deflators, $p_{j}$, using expenditure shares, $s_{i j}$, as weights:

$$
i c_{i} \equiv \sum_{j} p_{j} s_{i j}
$$

The value of intermediate consumption of each firm in sector $i$ in constant prices is, in turn, obtained by dividing its value in current prices by the corresponding intermediate consumption deflator, $i c_{i}$.

Value added in constant prices for each firm is simply the difference between the gross output of the firm and its intermediate consumption, both in constant prices.

The capital stock in the data set is reported at its end-of-period value in current prices. To convert these values into constant prices, I use information about capital stock in the initial year, values of investments in current prices in each year, and investment goods deflators. ${ }^{47}$ More specifically:

(i) The initial capital stock in constant prices is just the value of capital stock in current prices in the base year (1995).

(ii) New capital investment in constant prices is its value in current prices deflated by the appropriate capital goods deflator 48

(iii) Used capital investment in constant prices is its value in current prices deflated by the wholesale price index. The same deflator is used for the value of capital sold and depreciation.

\footnotetext{
${ }^{47}$ I construct separate deflators for four categories of capital goods: machines and equipment; buildings and structures; transport; and office equipment and other capital goods.

${ }^{48}$ The investments into new and used capital goods are usually reported separately.
} 
(iv) Net investment in constant prices is new investment in constant prices (from $(i i)$ ) + used investment in constant prices - value of capital goods sold in constant prices (from $($ iii)).

$(v)$ Beginning-of-period value of capital stock in constant prices for each year $t$ is the value of the initial capital stock in $(i)+$ cumulative value in $(i v)$ for all years $t$ - value of depreciation in constant prices for all years $t$.

\section{Other variables}

Employment is constructed as the year-average number of employees, including both white- and blue-collar employees (measured in man-years). This measure does not take into account differences in the efficiency of the two types of workers. To incorporate these differences, the efficiency of blue-collar workers can be normalized to 1 . Then, white-collar man-years can be converted into efficiency units using the ratio of the total wage bill of the white- to blue-collar workers. The sum of the two gives an alternative measure of the total employment in efficiency units.

\section{Estimation of Persistent Productivity Shocks}

The productivity shocks can be estimated under a more general formulation of the datagenerating process:

$$
\tilde{y}_{t}=\beta_{0}+\beta_{k} \tilde{k}_{t}+\beta_{n} \tilde{n}_{t}+\tilde{\omega}_{t}+\tilde{\epsilon}_{t}, \tilde{\eta}_{t} \sim \text { i.i.d. } \mathrm{N}\left(0, \sigma_{\epsilon}^{2}\right) \text {, and } \tilde{\omega}_{t}=\mathrm{E}\left[\tilde{\omega}_{t} \mid \tilde{\omega}_{t-1}\right]+\tilde{\eta}_{t} .
$$

Then the two stages of estimation following OP and LP would be modified accordingly to:

Stage 1:

$$
\tilde{y}_{t}=\beta_{n} \tilde{n}_{t}+\varphi\left(\tilde{k}_{t}, \tilde{i}_{t}\right)+\tilde{\epsilon}_{t}, \tilde{\epsilon}_{t} \sim \mathrm{N}\left(0, \sigma_{\epsilon}^{2}\right) \text {, where } \varphi\left(\tilde{k}_{t}, \tilde{i}_{t}\right)=\beta_{0}+\beta_{k} \tilde{k}_{t}+\tilde{\omega}_{t} \text {. }
$$


This equation can be estimated using OLS when $\tilde{n}_{t}$ is assumed to be uncorrelated with $\eta_{t}$, which is an untransmitted component of the contemporaneous disturbance. The function $\varphi$ can be approximated as previously by the polynomial of degree three in $\tilde{k}_{t}$ and $\tilde{i}_{t}$.

Stage 2:

$$
\tilde{y}_{t}-\hat{\beta}_{n} \tilde{n}_{t}=\beta_{0}+\beta_{k} \tilde{k}_{t}+\mathrm{E}\left[\tilde{\omega}_{t} \mid \tilde{\omega}_{t-1}\right]+\eta_{t}+\epsilon_{t} .
$$

This equation can be consistently estimated using OLS to obtain $\hat{\beta}_{k}$.

Using estimates of $\beta_{k}$ and $\beta_{n}$ from the two stages, one can then consistently predict the total i.i.d. component of the residuals given by

$$
\left(\tilde{\epsilon}_{t} \widehat{+} \tilde{\eta}_{t}\right)=\tilde{y}_{t}-\hat{\beta}_{n} \tilde{n}_{t}-\hat{\beta}_{k} \tilde{k}_{t}-E\left[\tilde{\omega}_{t} \mid \tilde{\omega}_{t-1}\right]
$$

Under the assumptions on the dynamics of productivity, the two i.i.d. error components could further be separated to find the variance of the transmitted idiosyncratic component, $\xi_{t}$. In particular, $\eta_{t}$ can be identified using the structure of the productivity shocks from

$$
\hat{\omega}_{t}=\hat{\varphi}_{t}-\hat{\beta}_{k} \tilde{k}_{t} \text { and } \omega_{t}=E\left[\omega_{t} \mid \omega_{t-1}\right]+\eta_{t}
$$

so that $\hat{\eta}_{t}=\hat{\varphi}_{t}-\hat{\omega}_{t}-E\left[\widehat{\omega}_{t \mid \omega_{t-1}}\right]$.

Then one can compute the estimated sample variance of the transmitted i.i.d. component of the productivity residuals. The advantage of this general specification with a persistent productivity component is that it provides full information about the distribution of productivity, including its persistent and idiosyncratic components. The estimated variance of the idiosyncratic component can be used in the model to parameterize the variance of the productivity shocks. The persistent part may be incorporated further; for example, its mean can be used as the level of aggregate total factor productivity in the individual production function of entrepreneurs. 


\section{Alternative Procedures for the Estimation of Pro- ductivity Shocks}

\section{D.1 Collinearity}

One concern about the two-stage estimation technique using OP/LP is the identifiability of the coefficient on labor in the first stage of estimation. The non-parametric function for investment is given by $i_{t}=f\left(\eta_{t}, k_{t}\right)$, so that $\eta_{t}=f^{-1}\left(i_{t}, k_{t}\right)$. Even with no specific functional form assumptions on the production function, the most obvious formulation for the demand for labor input is also a function of $\eta_{t}$ and $k_{t}$, i.e. $n_{t}=f\left(\eta_{t}, k_{t}\right)$. This means that $n_{t}$ does not vary independently of the non-parametric function being estimated, leading to collinearity and potential non-identifiability of the coefficient on labor $\beta_{n}$. Several approaches have been proposed to address the issue of collinearity, with two of the methods by Wooldridge (2005) and Gandhi, Navarro, and Rivers (2011) described below.

The approach suggested by Wooldridge (2005), appropriately modified for the purposes of this paper, uses the following estimating equations and orthogonality conditions: Equation 1:

$$
\tilde{y}_{t}=\tilde{\beta}_{0}+\beta_{k} \tilde{k}_{t}+\beta_{n} \tilde{n}_{t}+g\left(\tilde{i}_{t}, \tilde{k}_{t}\right)+\tilde{u}_{t},
$$

with orthogonality condition

$$
E\left\{\tilde{u}_{t} \mid \tilde{n}_{t}, \tilde{k}_{t}, \tilde{n}_{t-1}, \tilde{k}_{t-1}, \ldots, \tilde{n}_{1}, \tilde{k}_{1}\right\}=0 .
$$

Equation 2:

$$
\tilde{y}_{t}=\tilde{\beta}_{0}+\beta_{k} \tilde{k}_{t}+\beta_{n} \tilde{n}_{t}+\tilde{v}_{t},
$$

where $\tilde{v}_{t}=\tilde{\eta}_{t}+\tilde{u}_{t}$ with orthogonality condition

$$
E\left\{\tilde{v}_{t} \mid \tilde{k}_{t}, \tilde{n}_{t-1}, \tilde{k}_{t-1}, \ldots, \tilde{n}_{1}, \tilde{k}_{1}\right\}=0
$$


In other words, in (28) and (30) one can use the contemporaneous variable for capital, and any lags and functions thereof and of the labor input as instrumental variables. One can also add further proxy variables. In particular, in (27) the lag of labor input can be used as an instrument for $\tilde{n}_{t}$ to deal with the issue of collinearity. This allows one to identify the coefficient on labor input $\beta_{n}$ and the coefficients of the non-parametric function $\beta_{k} \tilde{k}_{t}+g\left(\tilde{i}_{t}, \tilde{k}_{t}\right)$. As mentioned previously, specifying the input demand equation allows one to separate $\tilde{\eta}_{t}$ from $\tilde{u}_{t}$ in $\tilde{v}_{t}$. Equation 29 can be used to estimate the coefficient on capital $\beta_{k}$ when $\tilde{n}_{t}$ is instrumented with its lag, since labor is a variable input and responds to productivity shocks $\tilde{\eta}_{t}$

An alternative approach is suggested by Gandhi, Navarro, and Rivers (2011). They use explicitly the first-order condition of the profit-maximizing firm with respect to the variable input traded in the competitive market, together with the production function, to get around the collinearity issue. Their system of equations is given by

$$
\ln \left(\frac{w_{t} \tilde{n}_{t}}{p_{t} \tilde{y}_{t}}\right)=\beta_{n}-\tilde{u}_{t} \text { and } \tilde{y}_{t}=\beta_{0}+\beta_{k} \tilde{k}_{t}+\beta_{n} \tilde{n}_{t}+\tilde{\eta}_{t}+\tilde{u}_{t}
$$

Letting $s_{t}=\ln \left(\frac{w_{t} \tilde{n}_{t}}{p_{t} \tilde{y}_{t}}\right)$ and $x_{t}=\left(\tilde{n}_{t}, \tilde{k}_{t}\right)$, the above system can be expressed as

$$
\left(\begin{array}{c}
s_{t} \\
\tilde{y}_{t}
\end{array}\right)=\Upsilon\left(x_{t}, \tilde{\eta}_{t}, \tilde{u}_{t}\right) .
$$

For any realization of the data $D_{t}=\left(s_{t}, \tilde{y}_{t}, \tilde{k}_{t}, \tilde{l}_{t}\right)$ and value of the parameter vector $\left(\beta_{k}, \beta_{n}\right)$, one can uniquely solve the two-equation system for the two unobservables for the econometrician $\tilde{\eta}_{t}$ and $\tilde{u}_{t}$, since it is a simple triangular system in $\left(\tilde{\eta}_{t}, \tilde{u}_{t}\right)$. To estimate the parameter vector, one can use the following moment conditions: $E\left\{\tilde{u}_{t}\right\}=0$ to estimate coefficient $\beta_{n}$ on labor, and $E\left\{\tilde{\eta}_{t} \tilde{k}_{t}\right\}=0$ to get the coefficient on capital, since $\tilde{k}_{t}$ is assumed to be a fixed input into the production function. Note that the system in two equations is needed here to be able to identify not only the coefficients on the fixed and variable inputs, but also to separate $\tilde{\eta}_{t}$ and $\tilde{u}_{t}$ from each other, since for the purposes of the paper, both the 
distribution of productivities $\tilde{\eta}_{t}$ and the coefficients of the production function $\beta_{n}$ and $\beta_{k}$ are needed.

\section{D.2 Robustness}

There are several potential sources of bias in the estimation, originating from the adopted assumptions, that need to be addressed with respect to their effect on the obtained estimates: (i) zero exit probability; (ii) i.i.d. productivity shocks; (iii) semi-parametric estimation with the productivity shocks only a function of current firm investment and capital stock, $\eta_{t}=g\left(k_{t}, i_{t}\right)$. These are addressed in turn.

(i) The fact that a firm's probability of exit is non-zero leads to downward bias in the estimate of the coefficient on capital, $\beta_{k}$. This is the case due to the negative correlation between capital stocks and productivity, since firms with larger capital stocks will be better suited to survive very low productivity realizations than their counterparts with smaller capital stocks. This negative correlation, in turn, would lead to a downward bias.

(ii) Persistence in productivity shocks would result in an upward bias in the estimate of the capital coefficient, since it would confound the effect of capital on output, with the effect that higher productivity realizations today would lead to an expectation of better productivity realization tomorrow and larger capital investment, to take advantage of this good productivity draw. This positive correlation between $k_{t+1}$ and $\eta_{t}$, which would be ignored in the second stage of estimation under the assumption of an i.i.d. shock, would result in a positive bias in the capital coefficient.

Thus, with assumptions of zero exit probability and i.i.d. productivity shocks, the resulting biases work in the opposite direction, so that the estimate of the coefficient in the model which abstracts from these assumptions may produce an estimate that is close to the actual as, in fact, shown in OP.

(iii) The assumption that investment demand can be expressed as a function of capital and productivity allows one to estimate the labor coefficient in the first stage of the estimation 
procedure. This estimate, in turn, affects the second-stage results where the new variable net of labor's contribution is formed to estimate the coefficient on capital input.

In particular, if the estimated coefficient $\hat{\beta}_{n}$ in the first stage is not the true coefficient $\beta_{n}$, the new dependent variable, $y_{t}-\hat{\beta}_{n} n_{t}$, would not subtract all of the effect of labor on output, leaving $\left(\beta_{n}-\hat{\beta}_{n}\right) n_{t}$ unaccounted for. Then, if one were to regress the "net" output $y_{t}-\hat{\beta}_{n} n_{t}$ on labor $n_{t}$, the coefficient $\gamma_{n}$ would be statistically significantly different from 0 , signalling that the investment function was misspecified.

Since $n_{t+1}$ endogenously responds to $\eta_{t+1}$, to test the investment function assumption one would instrument $n_{t+1}$ with $n_{t}$. This is a valid instrument given that: $(i) n_{t}$ is highly correlated with $n_{t+1}$, and (ii) $n_{t}$ is a static input (does not have dynamic implications), and thus is not correlated with $\tilde{\eta}_{t+1}$. In OP, the estimate of $\gamma_{n}$ above is not significant, and the other coefficients are barely changed from their previous values. 


\section{References}

Ábrahám, Á., And K. White (2006): "The Dynamics of Plant-level Productivity in U.S. Manufacturing," Working Paper CES 06-20, Center for Economic Studies, ftp://ftp2.census.gov/ces/wp/2006/CES-WP-06-20.pdf.

Ackerberg, D. A., K. Caves, and G. Fraser (2005): "Structural identification of production functions," Working paper.

Altunbaş, Y., and B. Gadanecz (2003): "Developing country economic structure and the pricing of syndicated credits," Working Paper 132, Bank for International Settlements.

Angeletos, G.-M. (2007): "Uninsured idiosyncratic investment risk and aggregate saving," Review of Economic Dynamics, 10, 1-30.

Antunes, A., T. Cavalcanti, and A. Villamil (2008): "The effect of financial repression and enforcement on entrepreneurship and economic development," Journal of Monetary Economics, 55, 278-297.

Arellano, C., Y. Bai, and J. Zhang (2012): "Firm Dynamics and Financial Development," Journal of Monetary Economics, 59, 533-539.

Asker, J., J. Farre-Mensa, and A. Ljungqvist (2014): "Comparing the Investment Behavior of Public and Private Firms," Discussion paper, ECGI Working Paper Series in Finance.

Atje, R., And B. Jovanovic (1993): "Stock markets and development," European Economic Review, 37(2-3), 632-640.

Campbell, J., M. Lettau, B. Malkiel, and Y. Xu (2001): "Have individual stocks become more volatile? An empirical exploration of idiosyncratic risk," Journal of Finance, $56,1-43$. 
Covas, F. (2006): "Uninsured idiosyncratic production risk with borrowing constraints," Journal of Economic Dynamics and Control, 30(11), 2167-2190.

Cubas, G., A. Ho, K. Huyhn, and D. Jacho-Chavez (2012): "Reallocation, Productivity, and the Ecuadorian Economic Crisis: Evidence from Firm-Level Data," Working paper, Kansas State University.

Davis, S. J., J. Haltiwanger, R. Jarmin, and J. Miranda (2006): "Volatility and dispersion in business growth rates: Publicly traded versus privately held firms," Macroeconomics Annual Volume 21, National Bureau of Economic Research.

DeBacker, J., B. Heim, V. Panousi, S. Ramnath, and I. Vidangos (2012): "The properties of income risk in privately held businesses," Working Paper 69, Federal Reserve Board.

DemirguÇ-Kunt, A., And R. Levine (2008): "Finance, financial sector policies, and long-run growth," Working Paper 4469, World Bank.

Devereux, M., And G. Smith (1994): "International risk sharing and economic growth," International Economic Review, 35(3), 535-550.

Eichengreen, B., And A. Mody (1999): "Lending booms, reserves, and the sustainability of short-term debt: Inferences from the pricing of syndicated bank loans," Discussion Paper 7113, National Bureau of Economic Research.

Gandhi, A., S. Navarro, and D. Rivers (2011): "On the Identification of Production Functions: How Heterogeneous is Productivity," Working paper, Western University.

Giné, X., And R. M. Townsend (2003): "Evaluation of financial liberalization: A general equilibrium model with constrained occupational choice," Working Paper 3014, World Bank. 
Greenwood, J., And B. Jovanovic (1990): "Financial development, growth, and the distribution of income," Journal of Political Economy, 98(5), 1076-1107.

Griliches, Z., and J. Mairesse (1995): "Production functions: The search for identification," Discussion Paper 5067, National Bureau of Economic Research.

Harberger, A. (1962): "The incidence of the corporation income tax," Journal of Political Economy, 70(3), 215-240.

Jeong, H., And R. M. Townsend (2007): "Sources of TFP growth: Occupational choice and financial deepening," Economic Theory, 32(1), 179-221.

Levinsohn, J., And A. Petrin (2003): "Estimating production functions using inputs to control for unobservables," Review of Economic Studies, 70(2), 317-341.

LiU, L. (1991): "Entry-Exit and productivity changes: An empirical analysis of efficiency frontiers," Ph.d. thesis, Department of Economics, University of Michigan.

Meн, C. (2008): "Business risk, credit constraints, and corporate taxation," Journal of Economic Dynamics and Control, 32(9), 2971-3008.

Meh, C., ANd V. QuAdrini (2006): "Endogenous market incompleteness with investment risks," Journal of Economic Dynamics and Control, 30(11), 2143-2165.

Obstfeld, M. (1994): "Risk-taking, global diversification, and growth," American Economic Review, 84(5), 1310-1329.

Olley, G. S., And A. Pakes (1996): "The dynamics of productivity in the telecommunications equipment industry," Econometrica, 64(6), 1263-1297.

WooldRidGe, J. M. (2005): "On estimating firm-level production functions using proxy variables to control for unobservables," Working papers, Department of Economics, Michigan State University. 